\title{
Structural basis for the inhibition of the eukaryotic ribosome
}

\author{
Nicolas Garreau de Loubresse ${ }^{1}$, Irina Prokhorova ${ }^{1}$, Wolf Holtkamp², Marina V. Rodnina ${ }^{2}$, Gulnara Yusupova ${ }^{1}$ \& Marat Yusupov ${ }^{1}$
}

The ribosome is a molecular machine responsible for protein synthesis and a major target for small-molecule inhibitors. Compared to the wealth of structural information available on ribosome-targeting antibiotics in bacteria, our understanding of the binding mode of ribosome inhibitors in eukaryotes is currently limited. Here we used $\mathrm{X}$-ray crystallography to determine 16 high-resolution structures of 80S ribosomes from Saccharomyces cerevisiae in complexes with 12 eukaryote-specific and 4 broad-spectrum inhibitors. All inhibitors were found associated with messenger RNA and transfer RNA binding sites. In combination with kinetic experiments, the structures suggest a model for the action of cycloheximide and lactimidomycin, which explains why lactimidomycin, the larger compound, specifically targets the first elongation cycle. The study defines common principles of targeting and resistance, provides insights into translation inhibitor mode of action and reveals the structural determinants responsible for species selectivity which could guide future drug development.

In all living cells, ribosomes are large ribonucleoprotein assemblies responsible for the accurate conversion of the genetic information encoded within mRNA into a corresponding protein. Although core functions of the ribosome are conserved in all kingdoms of life, eukaryotic ribosomes are at least $40 \%$ larger than their bacterial counterparts with a total mass ranging from $\sim 3.3 \mathrm{MDa}$ (yeasts and plants) up to $\sim 4.5 \mathrm{MDa}$ (mammals) $)^{1-3}$. The additional complexity of the eukaryotic ribosome structure is reflected in differences in terms of functions and aspects of translation and its regulation ${ }^{4}$.

Given the central role of the ribosome in the cell, living organisms have elaborated defence strategies using small-molecule inhibitors to impair ribosomal functions. Decades of studies have revealed the great diversity of molecular mechanisms used by a multitude of antibacterial agents (antibiotics) ${ }^{5,6}$. Atomic structures of prokaryotic ribosomes provided the basis for the development of novel antibiotics and in turn ribosome inhibitors served as tools to study protein synthesis in bacteria ${ }^{7}$. Similarly, the eukaryotic ribosome is a major target for broad-spectrum and eukaryote-specific small-molecule inhibitors isolated from natural sources. Despite limited understanding of their molecular mechanism, eukaryote-specific ribosomal inhibitors are increasingly used in research and hold potential for new therapeutics against a wide range of infectious diseases, cancers and genetic disorders ${ }^{8-12}$.

To date, no structural data are available for small-molecule inhibitors in complexes with either the complete eukaryotic ribosome or its subunits. Some eukaryote-specific inhibitors were investigated using crystals of the 50S subunit of the archaea Haloarcula marismortrui given its similarity with some parts of the eukaryotic ribosome ${ }^{13,14}$. A previous $\mathrm{X}$-ray study of the large subunit of Tetrahymena thermophila did not succeed to unambiguously place cycloheximide in its density due to limited resolution ${ }^{15}$. To gain insight into the mode of action of ribosome inhibitors in eukaryotes and to identify principles for drug development, we determined 16 crystal structures at high resolution, up to $2.9 \AA$, of the $S$. cerevisiae $80 \mathrm{~S}$ ribosome in complexes with 12 eukaryote-specific and 4 broad-spectrum inhibitors (Fig. 1, Extended Data Figs 1-3 and Extended Data Table 1). The broad-spectrum inhibitors target the peptidyl transferase centre on the large subunit (blasticidin S), the decoding centre (geneticin G418) and the mRNA-tRNA binding site on the small subunit (pactamycin, edeine). Eukaryotic-specific inhibitors were chosen on the basis of their capacity to alter cell proliferation and/or protein synthesis and their selectivity restricted to eukaryotes. The list comprises cycloheximide, lactimidomycin, phyllanthoside, $\mathrm{T}-2$ toxin, deoxynivalenol, verrucarin $\mathrm{A}$, narciclasine, lycorine, nagilactone $\mathrm{C}$, anisomycin, homoharringtonine and cryptopleurine.

The present study illustrates the chemical diversity of the smallmolecule inhibitors targeting the eukaryotic ribosome. All of them were systematically found in a clash with or in a close proximity to mRNA or transfer RNA (tRNA) binding sites on both subunits (Fig. 2a, b). In contrast to bacterial antibiotics, none were located in the peptide exit tunnel, which correlates with the increased number of rRNA modifications in this region of the eukaryotic ribosomes ${ }^{16}$. Although the $80 \mathrm{~S}$ ribosome contains 1.4 MDa of additional features absent in bacteria, it is noteworthy that all eukaryote-specific inhibitors target primary functional sites. This observation highlights the role of nucleotide substitutions in the formation of eukaryotic-specific pockets in the core of the machinery. Remarkably, the structures also explain the predominance of resistance mutations found in ribosomal proteins in or near the inhibitor binding sites (Extended Data Table 2). In contrast to bacteria, the high-copy number of rDNA in eukaryotic genomes limits the appearance of point mutations in rRNA. Instead, resistance mutations emerge exclusively within ribosomal proteins, encoded by one or two genes, sometimes located further away and separated by a layer of rRNA nucleotides like in the case of protein uL3. Consequently, development of drugs targeting the eukaryotic ribosome can be facilitated to prevent drug resistance by focusing on regions with the smallest number of proteins.

\section{The 60S tRNA E-site}

Among all three tRNA binding sites on the large subunit, the E-site is the most diverse across species, showing different nucleotide and protein content in bacteria, archaea and eukaryotes. Following peptide bond formation, this site accommodates deacylated tRNAs before their release in the cytoplasm. 
Eukaryote-specific

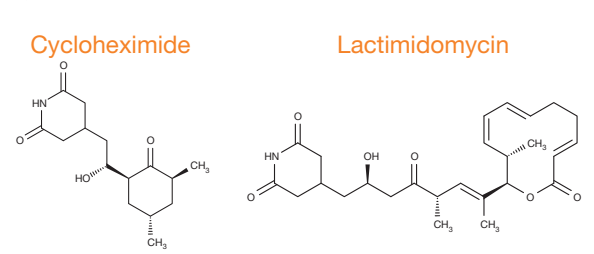

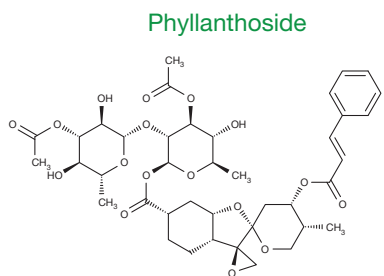<smiles>COc1ccc(CC2NCCC2C(=O)O)cc1</smiles>

Lycorine<smiles></smiles>

T-2 toxin

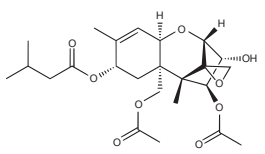

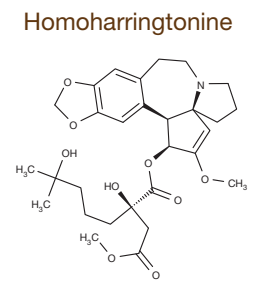

Verrucarin A

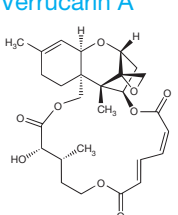

Figure $1 \mid$ Chemical structures of the 16 small-molecule inhibitors. a, Chemical structures of small-molecule inhibitors analysed in the study. Cycloheximide and lactimidomycin have an instrumental role in ribosome profiling experiments ${ }^{18,20}$. Homoharringtonine is a marketed drug for the treatment of chronic myeloid leukaemia ${ }^{37}$. Lycorine and narciclasine are

The glutarimide inhibitors, cycloheximide and lactimidomycin, were located in the E-site on the large subunit in a pocket formed by universally conserved nucleotides of the $25 \mathrm{~S}$ rRNA and a stretch of the eukaryote-specific protein eL42 (Fig. 3a). Lactimidomycin

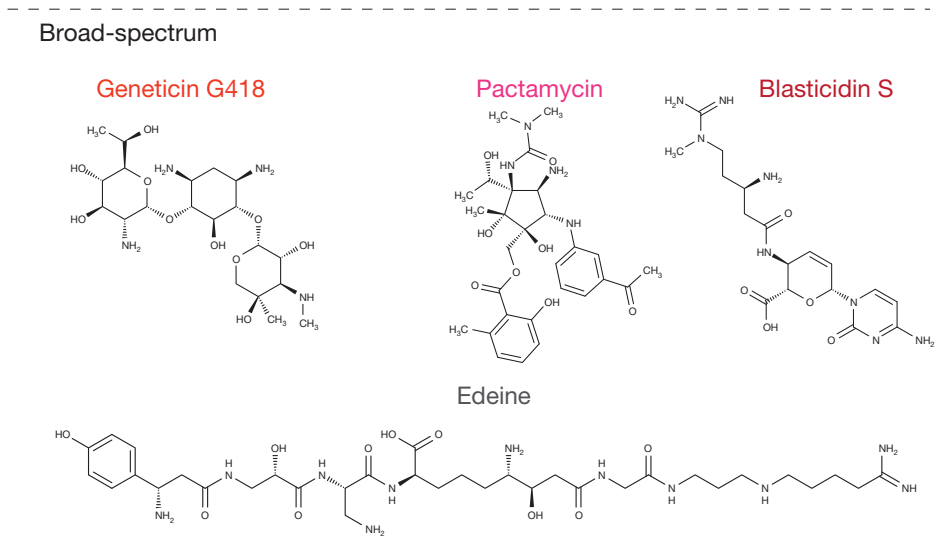

alkaloids known for their medicinal and toxic properties ${ }^{38}$. T-2 toxin, deoxynivalenol and verrucarin $A$ are widespread mycotoxins representatives of the three major trichothecenes subclasses ${ }^{39}$. The aminoglycoside geneticin (G418) promotes the read-through of premature termination codons ${ }^{11}$.

bears an additional lactone ring that is positioned on top of eL42 and directed towards the subunit interface. Although chemically unrelated to glutarimides, phyllanthoside makes contact with the same rRNA nucleotides and interacts with eL42 in a manner resembling the tRNA

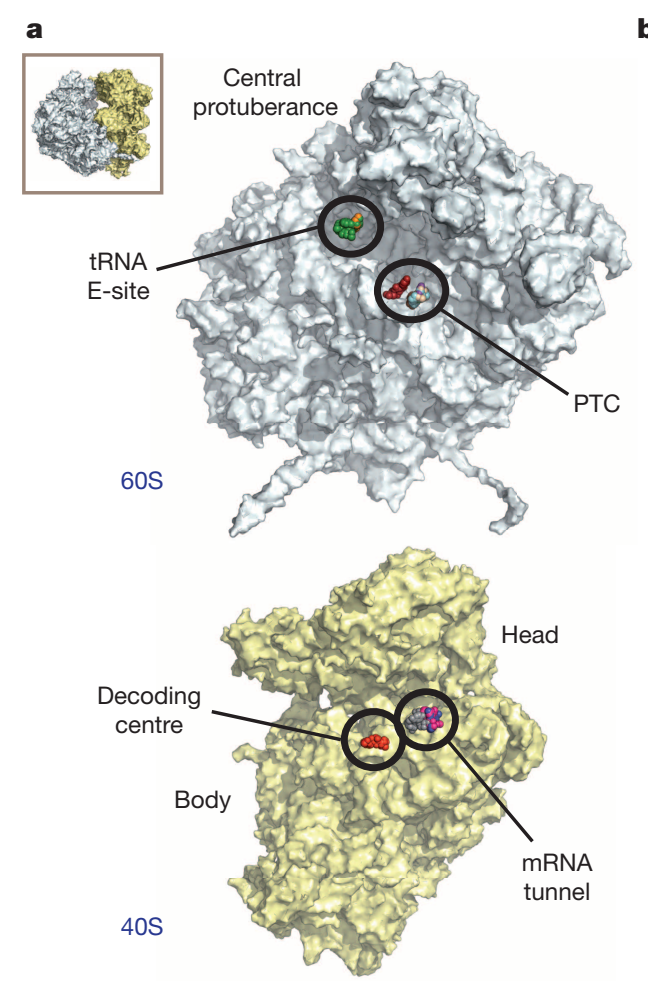

b
Figure $2 \mid$ Binding sites of inhibitors on the yeast ribosome. a, The binding sites can be grouped in four functional regions: the tRNA E-site and the peptidyl transferase centre (PTC) on the large subunit (60S) and the decoding centre (DC) and the mRNA channel on the small subunit (40S). View from

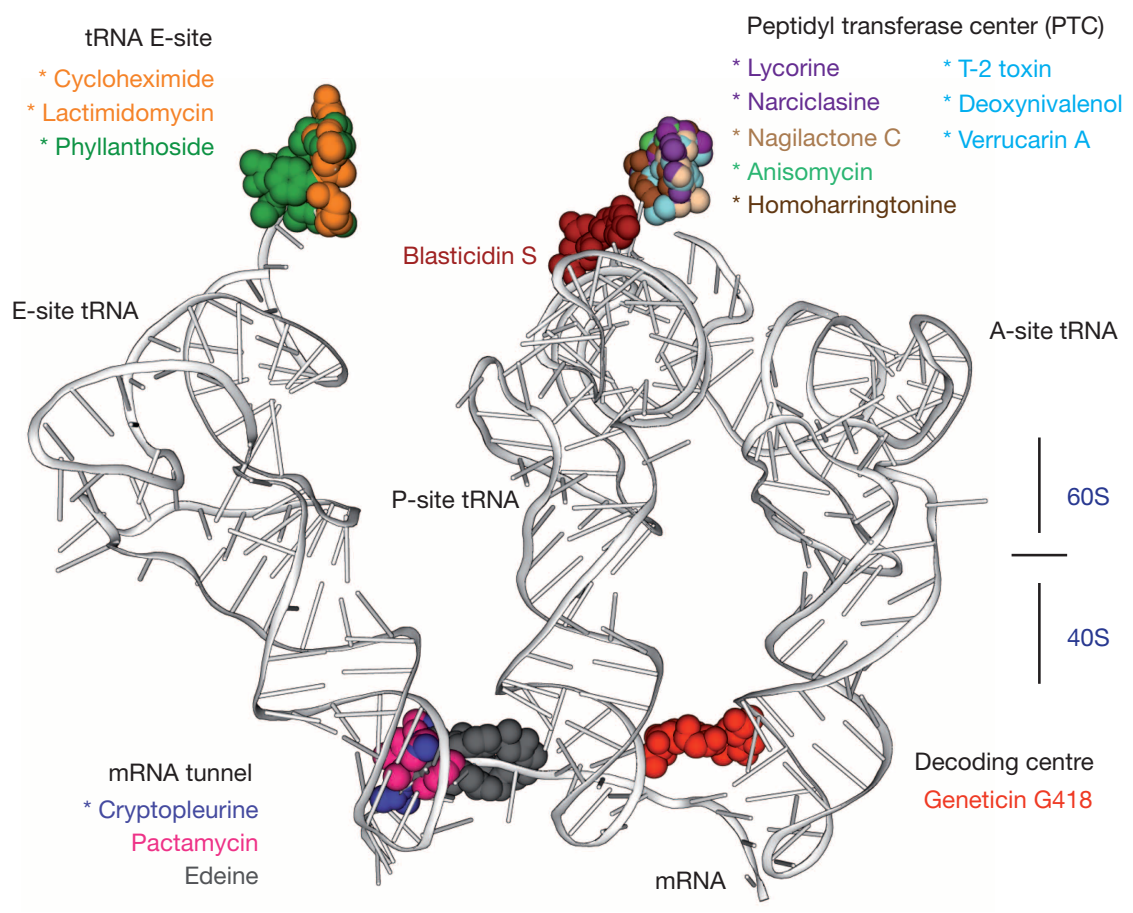

the subunit interface. $\mathbf{b}$, All inhibitors target mRNA and tRNA binding sites. The tRNAs and mRNA (white) structures were taken from the PDB (Protein Data Bank) entries 3I8I and 3I8H. Eukaryotic-specific inhibitors are marked with an asterisk. 

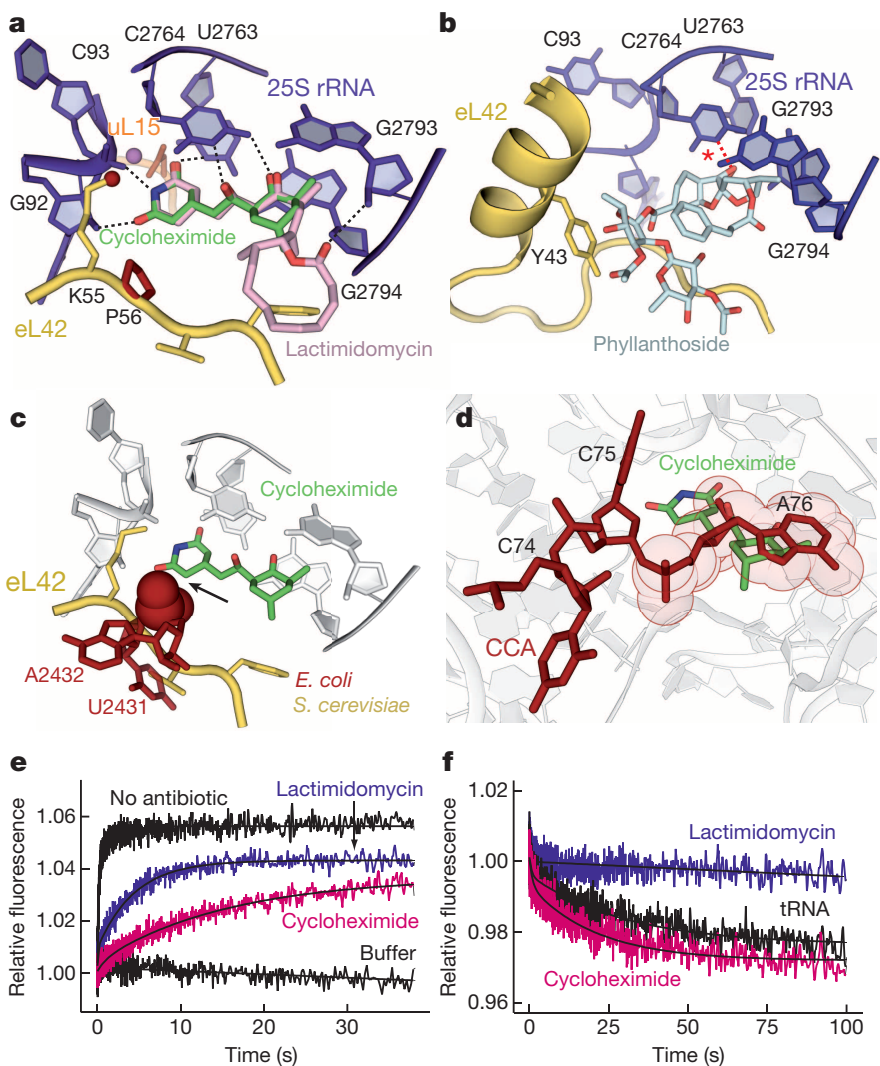

Figure $3 \mid$ Structure and function of 60S tRNA E-site inhibitors.

a, Cycloheximide (green) and lactimidomycin (pink) share the same binding site. Both structures are in agreement with resistance mutations in proteins eL42 (Pro 56) and uL15 (Gln 38) (red) and with the role of eL42 Lys 55 monomethylation (red sphere ${ }^{40-42}$. b. Binding site of phyllanthoside (light blue). The asterisk indicates a putative covalent bond. c, Two bacterial-specific nucleotides, U2431 and A2432, prevent the binding of E-site inhibitors to the bacterial ribosome (PDB accession codes: 2AVY, 2AW7). d, E-site inhibitors prevent the binding of deacylated tRNA. The CCA tri-nucleotide (red) mimics the acceptor end of the deacylated tRNA. e, Inhibition of tRNA binding to the $80 \mathrm{~S}$ E-site by lactimidomycin (blue) and cycloheximide (magenta). Controls without inhibitors (upper trace) and in the absence of 80 S ribosomes (lower trace) are also shown. $\mathbf{f}$, Dissociation of tRNA ${ }^{\text {Phe }}$ (Prf) from $80 \mathrm{~S}$ E-site as induced by addition of excess of non-labelled tRNA ${ }^{\text {Phe }}$ (black), cycloheximide (magenta) or lactimidomycin (blue).

CCA-end (Fig. 3b). The electron density suggests the presence of a covalent bond between C2764 (C2394, Escherichia coli numbering) and phyllanthoside epoxide group. This observation is consistent with the described irreversible effect of the inhibitor on protein synthesis ${ }^{17}$.

The strict selectivity of E-site inhibitors towards eukaryotes is explained by the presence of two bacterial-specific rRNA residues that occlude the binding pocket (Fig. 3c). In archaea, the orientation of the protein eL 42 on the large subunit of $H$. marismotui would most probably preclude the binding of lactimidomycin and phyllanthoside (Extended Data Fig. 4). To localize the position of the E-site tRNA on the large subunit, we solved the structure of the yeast ribosome in complex with the tri-nucleotide CCA that mimics the acceptor end of the deacylated tRNA (Extended Data Fig. 5). The structures explain previous biochemical data showing that cycloheximide and lactimidomycin compete with the binding of the tRNA CCA-end in the E-site of the large subunit ${ }^{18}$ (Fig. 3d). Phyllanthoside probably has a similar mode of inhibition ${ }^{17}$.

\section{S E-site accessibility for inhibitors}

Although cycloheximide and lactimidomycin bind to the same site and probably compete with the E-site tRNA, they affect translation in a different way. Lactimidomycin preferentially arrests ribosomes at the first peptide bond, whereas cycloheximide stalls ribosomes during ongoing translation ${ }^{18-20}$.

To better understand this difference, we used a rapid kinetic approach to study the effects of both inhibitors on tRNA binding to the E-site with a fluorescently labelled tRNA (proflavin (Prf) tRNA $\left.{ }^{\text {Phe }}\right)^{21}$. Binding of tRNA $^{\text {Phe }}$ (Prf) to the 80 S or 70 S ribosomes resulted in an almost identical rapid fluorescence change, reflecting the recruitment of the tRNA to the E-site, whereas transition from the E-site to the P-site was slow and not monitored (Extended Data Fig. 6a) ${ }^{22}$. When the ribosomes were pre-treated with lactimidomycin or cycloheximide, the rate of tRNA binding decreased, as expected for competitive inhibition (Fig. 3e). The apparent rates of tRNA binding decreased with the inhibitor concentration with a dose response curves, yielding $K_{\mathrm{i}}=2.7 \pm 0.7 \mu \mathrm{M}$ for lactimidomycin and $K_{\mathrm{i}}=0.1 \pm 0.05 \mu \mathrm{M}$ for cycloheximide (Extended Data Fig. 6b). Although the value for lactimidomycin was in agreement with the published data, cycloheximide appeared to have a much higher efficacy than reported for mammalian ribosomes using a footprinting technique ${ }^{18}$. Direct measurements of the binding affinity of cycloheximide to yeast ribosomes using isothermal titration calorimetry yielded a $K_{\mathrm{d}}=0.14 \pm 0.05 \mu \mathrm{M}$, in agreement with the result of our competition studies (Extended Data Fig. 6c).

Next, we tested whether the accessibility of the E-site plays a role. We followed the dissociation of $\mathrm{tRNA}^{\text {Phe }}$ (Prf) from $80 \mathrm{~S}$ ribosomes upon addition of cycloheximide or lactimidomycin (Fig. 3f). Upon addition of cycloheximide, tRNA $^{\text {Phe }}(\operatorname{Prf})$ was rapidly removed from the E-site, indicating that the inhibitor can rapidly exchange with tRNA. In contrast, lactimidomycin did not induce tRNA dissociation, suggesting that its binding to $80 \mathrm{~S}$ ribosomes is inhibited when the $\mathrm{E}$-site is occupied by deacylated tRNA. Clearly, tRNA ${ }^{\mathrm{Phe}}(\mathrm{Prf})$ can un-bind from the E-site within the observation time; however, its re-binding appears to be faster than the accommodation of lactimidomycin in the E-site. The structure of lactimidomycin with its additional lactone ring may obstruct the binding of the inhibitor to the E-site, making lactimidomycin a 'slow' inhibitor that can efficiently bind only in the absence of the physiological competitor, that is, during the first elongation cycle. Our data demonstrate that the size of the glutarimide compounds dictates their accessibility to the ribosome and consequently their mode of action.

\section{The peptidyl transferase centre}

Targeted by the majority of antibiotics, the catalytic centre of the ribosome located on the large subunit is exclusively composed of highly conserved rRNA nucleotides. The reaction of peptide bond formation requires the two substrates, that is, aminoacyl-tRNA and peptidyl-tRNA, to be properly aligned in the A-site and P-site of the peptidyl transferase centre, respectively.

In contrast to blasticidin S which binds in the P-site of the large subunit in the same way in bacteria and archaea, numerous eukaryotespecific inhibitors were found associated with the A-site of the peptidyl transferase centre (Fig. 4a and Extended Data Fig. 7) ${ }^{23}$. Remarkably, chemically diverse inhibitors share a similar mode of binding within the pocket. Upon binding, all A-site inhibitors induce a similar pattern of structural rearrangements in their direct vicinity that propagate up to $15 \AA$ away from the peptidyl transferase centre (Extended Data Fig. 8a). The common structural scaffold of trichothecenes inhibitors, represented by $\mathrm{T}-2$ toxin, deoxynivalenol and verrucarin $\mathrm{A}$, mediates all major contacts with rRNA residues in the binding pocket (Fig. 4b). The acetate-based substituents of T-2 toxin are pointing towards the peptide tunnel entrance, whereas the verrucarin A large macrocycle extends further towards the macrolide binding site in bacteria. Lycorine, narcilasine and homoharringtonine are plant alkaloids sharing similarities, including a dioxol-pyrroline group (Fig. 4c). In contrast to trichothecenes, the three alkaloids adopt a distinct conformation in the pocket where the dioxol-pyrroline group is positioned differently. These findings suggest that the dioxol-pyrroline group might play a specific role such as being a recognition motif for enzymes in the alkaloid 


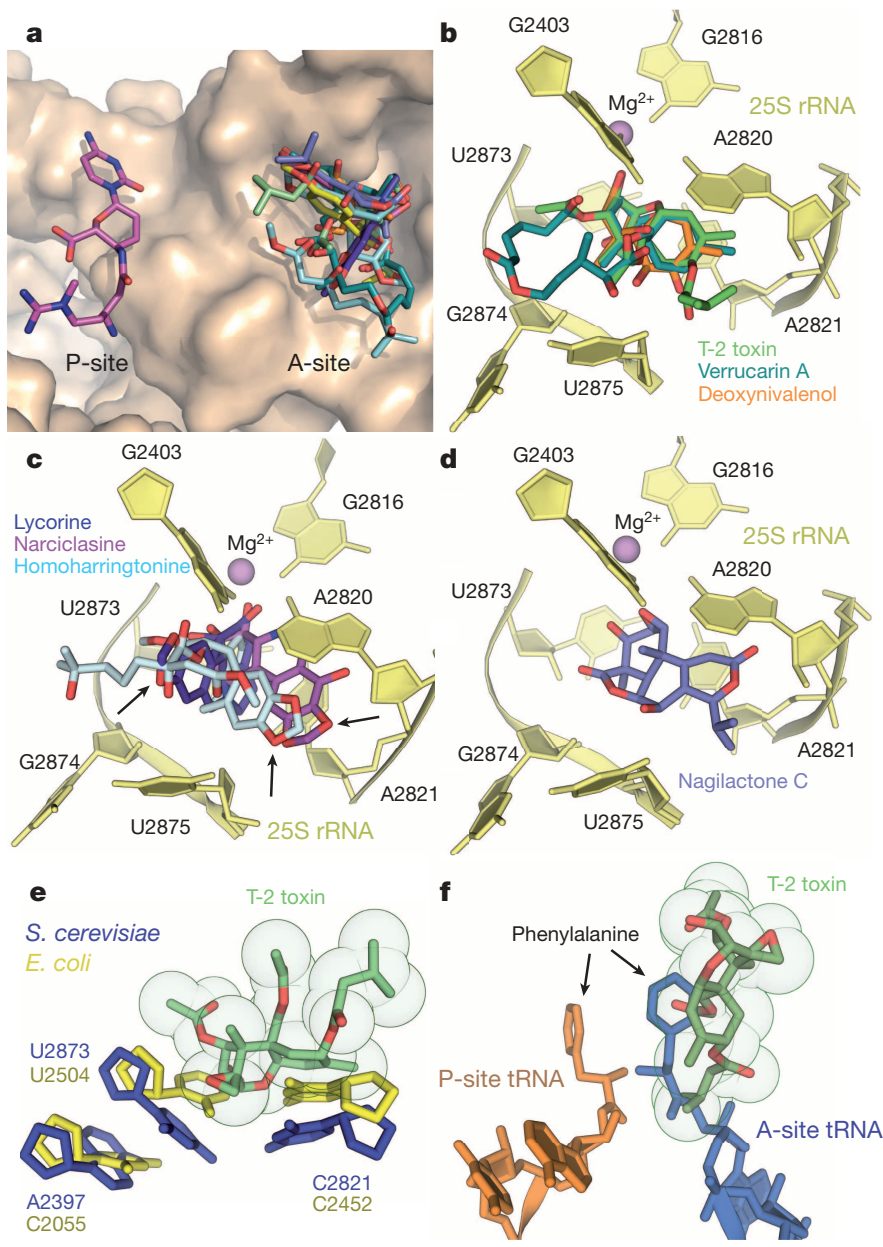

Figure 4 Structures of 60 S peptidyl transferase centre inhibitors.

a, Blasticidin $\mathrm{S}$ binds to the $60 \mathrm{~S}$ tRNA P-site, whereas T-2 toxin, deoxynivalenol, verrucarin A, lycorine, narciclasine, homoharringtonine, nagilactone $\mathrm{C}$ and anisomycin are clustered in the 60S tRNA A-site. b, Binding site of T-2 toxin (green), deoxynivalenol (orange) and verrucarin A (cyan).

c, Binding site of narcilasine (purple), lycorine (blue), homoharringtonine (pale cyan). The arrows highlight the location of the dioxol-pyrroline group. d, Binding site of nagilactone C (blue). e, The conformation of U2504 in bacteria (PDB accession codes: 2AVY, 2AW7) closes the binding site to the eukaryotic-specific A-site inhibitors. f, A-site inhibitors hinder aminoacyl-tRNA positioning in the peptidyl transferase centre. The Phe-tRNA structures were taken from PDB accession codes 2WDG, 2WDL.

biosynthetic pathway. Nagilactone $\mathrm{C}$ shares all the features of A-site inhibitors (Fig. 4d). Finally, homoharringtonine and anisomycin binding is conserved between archaea and eukaryotes; however, some variations were found in the anisomycin vicinity (Extended Data Fig. 8b).

Consistent with structural data obtained from the archaeal 50S subunit, the identity of $25 \mathrm{~S}$ rRNA residue 2397 (2055) is suggested to influence the conformation of U2873 (U2504) that dictates the binding of either bacterial-specific or eukaryotic-specific inhibitors (Fig. 4e) ${ }^{14}$. In bacteria, the residue 2397 (2055) is a cytosine, whereas an adenine is found in $96 \%$ of eukaryotes. Of therapeutic interest, the remaining $4 \%$ of eukaryotes might be sensitive to antibacterial drugs instead of eukaryotic inhibitors, such as Giardia species ${ }^{24}$. Most A-site inhibitors were found to impair peptide bond formation during translation elongation (Extended Data Table 1). Superimposition of aminoacyl-tRNA structures shows that the entrance of the amino acid moiety in the peptidyl transferase centre is hindered by the presence of A-site inhibitors (Fig. 4f).

\section{The decoding centre}

The decoding centre of the ribosome forms a geometrically restricted pocket that accurately selects aminoacyl-tRNA in accordance with
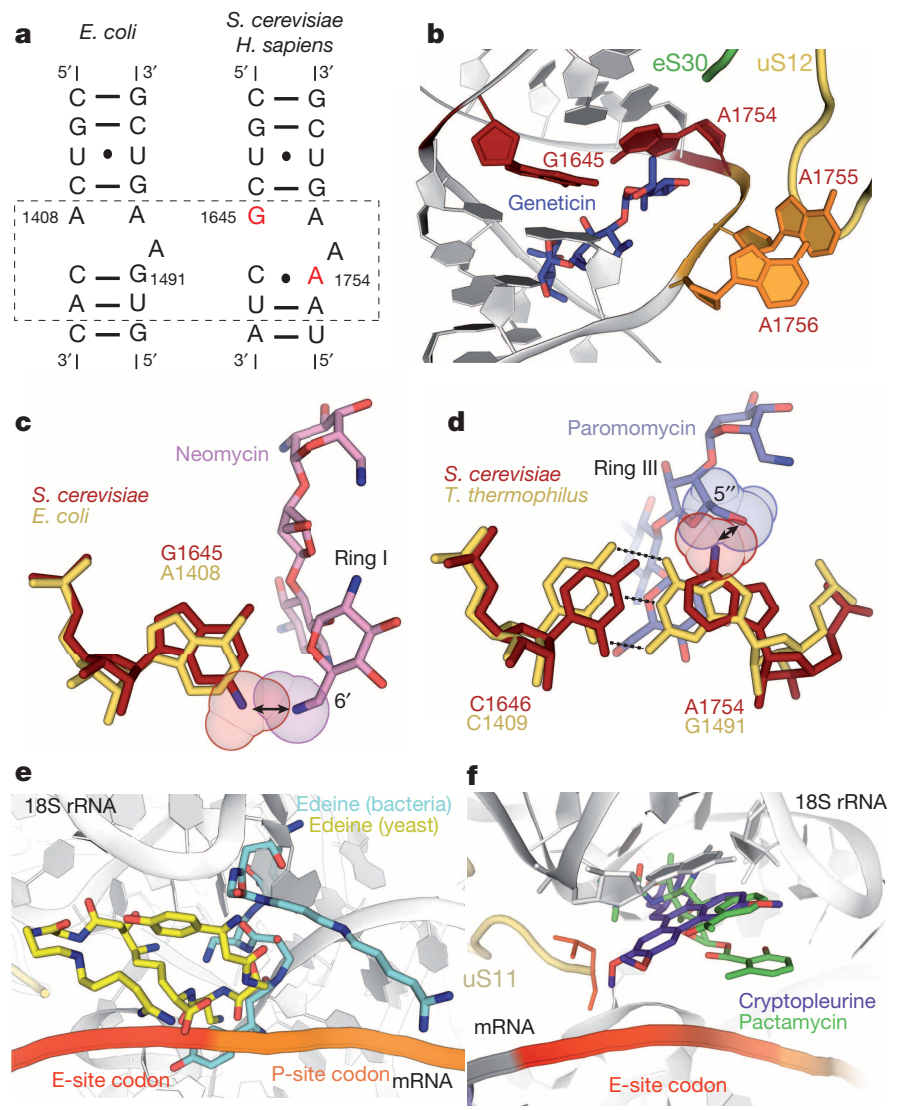

Figure $5 \mid$ Structures of 40S mRNA and tRNA inhibitors. a, The aminoglycosides binding site is different in eukaryotes. Secondary structure diagrams of helix 44 from bacteria (16S rRNA, left) and from yeast and human (18S rRNA, right). b, Geneticin (blue) binds to helix 44 and induces the flipping out of A1755 and A1756 (orange). c, The conformation of G1645 in yeast 18S rRNA restricts the binding of aminoglycosides bearing a $6^{\prime}$ amino group in ring I, as shown for neomycin (pink, PDB accession code: 3QAN). d, The conformation of A1754 in yeast restricts the binding of aminoglycosides bearing a $5^{\prime \prime}$ hydroxyl group in ring III, as shown for paromomycin (blue, PDB 3UZ3). e, Edeine adopts a different conformation on the bacterial (blue, PDB 1I95) and eukaryotic ribosome (yellow). f, Pactamycin (green) and cryptopleurine (purple) share the same binding site in the $40 \mathrm{~S}$ E-site. Natural mutations in the C-terminal part of protein uS11 (red) confer resistance to cryptopleurine ${ }^{43}$. The mRNA structure was taken from PDB accession code $4 \mathrm{KZZ}$.

mRNA codons positioned in the A-site ${ }^{25,26}$. In bacteria, aminoglycosides antibiotics alter translation accuracy and inhibit tRNA translocation by perturbing the conformation of the decoding centre nucleotides. Besides their potent activity against Gram-negative bacteria, the aminoglycoside-induced suppression of premature termination holds potential for the treatment of inherited disorders caused by nonsense mutations ${ }^{11,27}$.

The canonical aminoglycoside binding site is located within the internal loop of helix 44 of $18 \mathrm{~S}$ rRNA, which is part of the decoding centre that contains the essential and universally conserved nucleotides A1755 (A1492) and A1756 (A1493). In close vicinity, two nucleotides differ between bacteria and eukaryotes, but are identical in yeast and humans: G1645 (A1408) and A1754 (G1491) (Fig. 5a) ${ }^{28,29}$.

The large class of aminoglycosides can be divided in three subgroups according to their chemical structures: kanamycins, neomycins and gentamicins $s^{30}$. We chose geneticin (G418) as a representative of kanamycins with high affinity for the eukaryotic ribosome. Geneticin binds into the aminoglycoside pocket and induces the flipping out of A1755 and A1756 (Fig. 5b). The structure highlights direct interactions between geneticin ring I and the eukaryote-specific residues G1645 and A1754. 


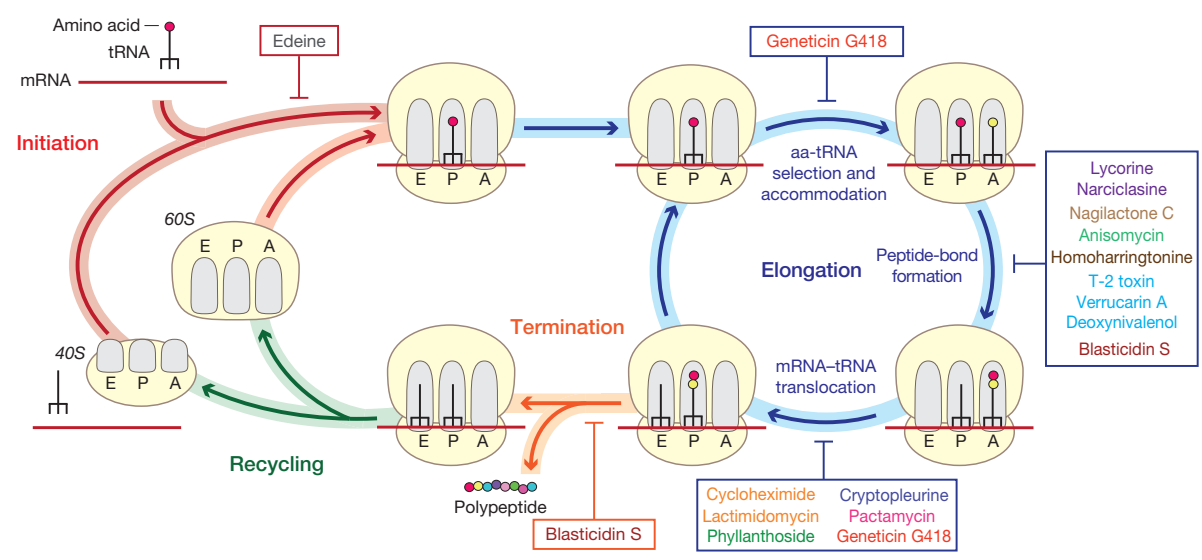

Figure 6 Inhibitors action during protein synthesis in eukaryotes. Schematic showing the steps of protein synthesis in eukaryotes impaired by the smallmolecule inhibitors.

Although some aminoglycosides exhibit broad-spectrum activity against both bacteria and eukaryotes, most of them remain poorly or not active on eukaryotic cytosolic ribosomes. This resistance mechanism observed within the class is attributed to the aforementioned structural differences present in eukaryotes. We demonstrate that the conformation of G1645, which is different from the conformation of A1408 in bacteria, acts as a barrier on the eukaryotic ribosome by preventing the accommodation of aminoglycosides with a 6 ' -substituent in ring I different from hydroxyl (Fig. 5c). This finding confirms previous results on low inhibitory activity of aminoglycosides in eukaryotes ${ }^{31}$. In line with this, most kanamycins and all gentamicins contain an amino group or a carbon side chain at this position responsible for their limited effect on the eukaryotic ribosome. However, some members of the neomycin family, such as paromomycin, contain a $6^{\prime}$ hydroxyl substituent and yet remain poorly active on the cytosolic eukaryotic ribosomes. We identified a second structural barrier to neomycin binding: in comparison to bacteria, A1754 is shifted in eukaryotes due to a non-canonical interaction with C1646. Consequently, A1754 prevents the accommodation of the $5^{\prime \prime}$-hydroxyl group in ring III sometimes present in neomycins, which provides an explanation for the biochemical data (Fig. 5d) ${ }^{28}$.

\section{The mRNA and tRNA binding sites}

Additional rRNA elements and proteins have led to important remodelling of the small subunit structure in eukaryotes, which serves as a platform for numerous protein factors and participates actively in translation initiation. During initiation, the subunit binds to and moves along the mRNA 5' untranslated region to search for the proper start codon.

In bacteria, edeine binds between the P-site and the E-site of the small subunit and impairs the binding of initiator tRNA to the P-site during initiation ${ }^{32,33}$. In the yeast ribosome, edeine binds to the same region but adopts a markedly different conformation than on the bacterial 30S subunit (Fig. 5e). Located almost exclusively in the E-site, the binding pocket is formed by $18 \mathrm{~S}$ rRNA nucleotides positioned in the mRNA path. Edeine affects translation differently in prokaryotes and eukaryotes in keeping with the fact that the mechanism of initiation is markedly distinct. Indeed, edeine interferes with start codon recognition by promoting continuous scanning of the $40 \mathrm{~S}$ subunit and preventing subunit joining ${ }^{34}$. Thus, mRNA and edeine may simultaneously bind to the $40 \mathrm{~S}$ subunit to promote scanning and prevent initiator tRNA interaction with the start codon.

Pactamycin and cryptopleurine are located exclusively in the $40 \mathrm{~S}$ E-site and share the same binding pocket that overlaps in part with the edeine binding site. Both inhibitors are found in the mRNA channel in the E-site and interact with the ribosome by stacking with the residue G904 of 18 S rRNA (Fig. 5f). Pactamycin is a broad-spectrum inhibitor with binding mode conserved in bacteria and eukaryotes. On the other hand, cryptopleurine was described as a eukaryote-specific inhibitor $^{35}$. The structure of cryptopleurine bound to yeast ribosome in the present functional state does not provide the basis for its specificity. The location of pactamycin and cryptopleurine imply that they act on the step of translocation from the P-site to the E-site and may also affect initiation in eukaryotes. It remains to be shown whether the translocation inhibition is promoted by hindering mRNA and/or tRNA movement.

\section{Conclusions}

This study provides a complete atomic description of 16 inhibitors bound to the yeast ribosome, highlighting common principles of targeting and shedding light on their binding sites, modes of action, determinants of species selectivity and resistance. By targeting exclusively mRNA and tRNA binding sites on both subunits, small-molecule inhibitors impair several ribosome functions mainly, but not exclusively, during the elongation cycle (Fig. 6).

In conjunction with kinetic experiments, we demonstrate that the size of glutarimide inhibitors dictates their binding to the ribosome at specific stages of elongation, resulting in different effects on translation. This model may have direct implications for other ribosome inhibitors in eukaryotes and in bacteria. For example, in the peptidyl transferase centre A-site, a similar mechanism may explain why anisomycin (small) and homoharringtonine (large) share the same binding site but block different stages of elongation ${ }^{36}$.

Similarly to antibiotics acting against the bacterial ribosome, $80 \mathrm{~S}$ ribosome inhibitors are sophisticated tools to study protein synthesis in eukaryotes ${ }^{20}$. Our study highlights general principles for drug targeting and provides foundations for structure-based drug design. These structures will facilitate the development of next-generation antibiotics with reduced adverse effects and new therapeutics against infectious diseases, cancers and genetic disorders caused by premature termination codons ${ }^{8-12}$. High-resolution X-ray crystallography of the $80 \mathrm{~S}$ ribosome opens a new area of investigation-a large number of ribosome inhibitors certainly remain to be discovered and analysed.

Online Content Methods, along with any additional Extended Data display items and Source Data, are available in the online version of the paper; references unique to these sections appear only in the online paper.

Received 7 May; accepted 6 August 2014.

Published online 10 September 2014.

1. Ben-Shem, A. et al. The structure of the eukaryotic ribosome at $3.0 \AA$ A resolution. Science 334, 1524-1529 (2011).

2. Melnikov, S. etal. One core, two shells: bacterial and eukaryotic ribosomes. Nature Struct. Mol. Biol. 19, 560-567 (2012).

3. Jenner, L. et al. Crystal structure of the 80 S yeast ribosome. Curr. Opin. Struct. Biol. 22, 759-767 (2012). 
4. Sonenberg, N. \& Hinnebusch, A. G. Regulation of translation initiation in eukaryotes: mechanisms and biological targets. Cell 136, 731-745 (2009).

5. Wilson, D. N. Ribosome-targeting antibiotics and mechanisms of bacterial resistance. Nature Rev. Microbiol. 12, 35-48 (2014).

6. Blaha, G. M., Polikanov, Y. S. \& Steitz, T. A. Elements of ribosomal drug resistance and specificity. Curr. Opin. Struct. Biol. 22, 750-758 (2012).

7. Zhou, J. et al. Design at the atomic level: generation of novel hybrid biaryloxazolidinones as promising new antibiotics. Bioorg. Med. Chem. Lett. 18, 6179-6183 (2008)

8. Hobbie, S. N. et al. Genetic reconstruction of protozoan rRNA decoding sites provides a rationale for paromomycin activity against Leishmania and Trypanosoma. PLoS Negl. Trop. Dis. 5, e1161 (2011).

9. Lu, W., Roongsawang, N. \& Mahmud, T. Biosynthetic studies and genetic engineering of pactamycin analogs with improved selectivity toward malarial parasites. Chem. Biol. 18, 425-431 (2011).

10. Santagata, S. et al. Tight coordination of protein translation and HSF1 activation supports the anabolic malignant state. Science 341, 1238303 (2013).

11. Bidou, L., Allamand, V., Rousset, J. P. \& Namy, O. Sense from nonsense: therapies for premature stop codon diseases. Trends Mol. Med. 18, 679-688 (2012).

12. Darnell, J. C. \& Klann, E The translation of translational control by FMRP. therapeutic targets for FXS. Nature Neurosci. 16, 1530-1536 (2013).

13. Gürel, G., Blaha, G., Steitz, T. A. \& Moore, P. B. Structures of triacetyloleandomycin and mycalamide $A$ bind to the large ribosomal subunit of Haloarcula marismortui. Antimicrob. Agents Chemother. 53, 5010-5014 (2009).

14. Gürel, G., Blaha, G., Moore, P. B. \& Steitz, T. A. U2504 determines the species specificity of the A-site cleft antibiotics: the structures of tiamulin, homoharringtonine, and bruceantin bound to the ribosome. J. Mol. Biol. 389 , 146-156 (2009).

15. Klinge, S., Voigts-Hoffmann, F., Leibundgut, M., Arpagaus, S. \& Ban, N. Crystal structure of the eukaryotic 605 ribosomal subunit in complex with initiation factor 6. Science 334, 941-948 (2011).

16. Decatur, W. A. \& Fournier, M. J. rRNA modifications and ribosome function. Trends Biochem. Sci. 27, 344-351 (2002)

17. Chan, J., Khan, S. N., Harvey, I., Merrick, W. \& Pelletier, J. Eukaryotic protein synthesis inhibitors identified by comparison of cytotoxicity profiles. RNA 10, 528-543 (2004)

18. Schneider-Poetsch, T. et al. Inhibition of eukaryotic translation elongation by cycloheximide and lactimidomycin. Nature Chem. Biol. 6, 209-217 (2010).

19. Lee, S., Liu, B., Huang, S. X., Shen, B. \& Qian, S. B. Global mapping of translation initiation sites in mammalian cells at single-nucleotide resolution. Proc. Natl Acad. Sci. USA 109, E2424-E2432 (2012).

20. Ingolia, N. T., Ghaemmaghami, S., Newman, J. R. \& Weissman, J. S. Genome-wide analysis in vivo of translation with nucleotide resolution using ribosome profiling. Science 324, 218-223 (2009)

21. Wintermeyer, W. \& Zachau, H. G. Fluorescent derivatives of yeast tRNAPhe Eur. J. Biochem. 98, 465-475 (1979).

22. Lill, R., Robertson, J. M. \& Wintermeyer, W. Affinities of tRNA binding sites of ribosomes from Escherichia coli. Biochemistry 25, 3245-3255 (1986).

23. Svidritskiy, E., Ling, C., Ermolenko, D. N. \& Korostelev, A. A. Blasticidin S inhibits translation by trapping deformed tRNA on the ribosome. Proc. Natl Acad. Sci. USA 110, 12283-12288 (2013).

24. Cannone, J. J. et al. The comparative RNA web (CRW) site: an online database of comparative sequence and structure information for ribosomal, intron, and other RNAs. BMC Bioinformatics 3, 2 (2002).

25. Demeshkina, N., Jenner, L., Westhof, E., Yusupov, M. \& Yusupova, G. A new understanding of the decoding principle on the ribosome. Nature 484, 256-259 (2012).

26. Ogle, J. M., Murphy, F. V., Tarry, M. J. \& Ramakrishnan, V. Selection of tRNA by the ribosome requires a transition from an open to a closed form. Cell 111, 721-732 (2002).

27. Shulman, E. et al. Designer aminoglycosides that selectively inhibit cytoplasmic rather than mitochondrial ribosomes show decreased ototoxicity: a strategy for the treatment of genetic diseases. J. Biol. Chem. 289, 2318-2330 (2014).

28. Fan-Minogue, H. \& Bedwell, D. M. Eukaryotic ribosomal RNA determinants of aminoglycoside resistance and their role in translational fidelity. RNA 14, 148-157 (2008).

29. Recht, M. I., Douthwaite, S. \& Puglisi, J. D. Basis for prokaryotic specificity of action of aminoglycoside antibiotics. EMBO J. 18, 3133-3138 (1999).

30. Becker, B. \& Cooper, M. A. Aminoglycoside antibiotics in the 21 st century. ACS Chem. Biol. 8, 105-115 (2013).
31. Perez-Fernandez, D. et al. 4'-O-substitutions determine selectivity of aminoglycoside antibiotics. Nature Commun. 5, 3112 (2014).

32. Dinos, G. et al. Dissecting the ribosomal inhibition mechanisms of edeine and pactamycin: the universally conserved residues $\mathrm{G} 693$ and $\mathrm{C} 795$ regulate $\mathrm{P}$-site RNA binding. Mol. Cell 13, 113-124 (2004).

33. Pioletti, M. et al. Crystal structures of complexes of the small ribosomal subunit with tetracycline, edeine and IF3. EMBO J. 20, 1829-1839 (2001).

34. Kozak, M. \& Shatkin, A. J. Migration of 40 S ribosomal subunits on messenger RNA in the presence of edeine. J. Biol. Chem. 253, 6568-6577 (1978).

35. Dölz, H., Vazquez, D. \& Jimenez, A. Quantitation of the specific interaction of [14a-3H]cryptopleurine with $80 \mathrm{~S}$ and $40 \mathrm{~S}$ ribosomal species from the yeast Saccharomyces cerevisiae. Biochemistry 21, 3181-3187 (1982)

36. Ingolia, N. T., Lareau, L. F. \& Weissman, J. S. Ribosome profiling of mouse embryonic stem cells reveals the complexity and dynamics of mammalian proteomes. Cell 147, 789-802 (2011)

37. Chen, Y. \& Li, S. Omacetaxine mepesuccinate in the treatment of intractable chronic myeloid leukemia. Onco Targets Ther 7, 177-186 (2014).

38. Evidente, A. et al. Biological evaluation of structurally diverse amaryllidaceae alkaloids and their synthetic derivatives: discovery of novel leads for anticancer drug design. Planta Med. 75, 501-507 (2009).

39. McCormick, S. P., Stanley, A. M., Stover, N. A. \& Alexander, N. J. Trichothecenes: from simple to complex mycotoxins. Toxins 3, 802-814 (2011).

40. Shirai, A., Sadaie, M., Shinmyozu, K. \& Nakayama, J. Methylation of ribosomal protein $L 42$ regulates ribosomal function and stress-adapted cell growth. J. Biol. Chem. 285, 22448-22460 (2010)

41. Kawai, S. etal. Drastic alteration of cycloheximide sensitivity by substitution of one amino acid in the L41 ribosomal protein of yeasts. J. Bacteriol. 174, 254-262 (1992).

42. Kaàufer, N. F., Fried, H. M., Schwindinger, W. F., Jasin, M. \& Warner, J. R. Cycloheximide resistance in yeast: the gene and its protein. Nucleic Acids Res. 11 3123-3135 (1983).

43. Sánchez, L., Vásquez, D. \& Jiménez, A. Genetics and biochemistry of cryptopleurine resistance in the yeast Saccharomyces cerevisiae. Mol. Gen. Genet. 156, 319-326 (1977)

Supplementary Information is available in the online version of the paper.

Acknowledgements We thank J. Liu (Johns Hopkins Medical Institute), D. Wilson (Gene Center Munich), P. Hazendonk (Agriculture and Agri-Food Canada) and the $\mathrm{NIH} / \mathrm{NCl}$ Developmental Therapeutics Program for providing materials. We acknowledge SOLEIL synchrotron (France), all staff members of PROXIMA1 beamline, especially A. Thompson and P. Legrand for their assistance during data collection. We thank A. Perez Lara, MPI Göttingen, for the help with the ITC experiments and S. Melnikov, IGBMC, for reading the manuscript. I.P. acknowledges support from AFM-Telethon post-doctoral fellowship. This work was supported by the SATT Conectus Technology Maturation grant I12-042 (to N.G.D.L.), the ERC Advanced grant 294312, the Human Frontier Science Program grant RGP0062/2012 and the Russian Government Program of Competitive Growth of Kazan Federal University (to M.Y.), the French National Research Agency grant ANR-11-BSV8-006 01 (to G.Y.) and the Deutsche Forschungsgemeinschaft grant (to M.V.R.).

Author Contributions M.Y. supervised the study. N.G.D.L. designed the experiments N.G.D.L. and I.P. conducted purification, crystallization and post-crystallization treatment experiments, collected X-ray diffraction data and carried out the structure determination. N.G.D.L., I.P., G.Y. and M.Y. analysed the crystal structures. M.V.R. and W.H. designed, performed and interpreted rapid kinetic experiments. N.G.D.L. wrote the initial manuscript to which M.V.R., G.Y. and M.Y. contributed specialist insights. All authors helped with refining the manuscript and approved the final version.

Author Information Atomic coordinates and structure factors for the reported crystal structures have been deposited in the Protein Data Bank (http://www.pdb.org/pdb/home/home.do) under accession codes 4U3M (anisomycin), 4U56 (blasticidin S), 4U3N (CCA), 4 U55 (cryptopleurine), 4U3U (cycloheximide), 4U53 (deoxynivalenol), 4U4N (edeine), 4U4O (geneticin G418), 4U4Q (homoharringtonine), 4U4R (lactimidomycin), 4U4U (lycorine), 4U52 (nagilactone C), 4U51 (narcilasine), 4U4Y (pactamycin), 4U4Z (phyllanthoside), 4U6F (T-2 toxin) and $4 U 50$ (verrucarin). Reprints and permissions information is available at www.nature.com/reprints. The authors declare no competing financial interests. Readers are welcome to comment on the online version of the paper. Correspondence and requests for materials should be addressed to M.Y. (marat@igbmc.fr). 


\section{METHODS}

Reagents. Lactimidomycin was provided by Jon Liu (Johns Hopkins Medical Institute), edeine by Daniel Wilson (Gene Center Munich) and T-2 toxin by Paul Hazendonk (Agriculture and Agri-Food Canada). Lycorine, homoharringtonine and narciclasine were ordered from Santa Cruz Biotech. Anisomycin, pactamycin, blasticidin S, cycloheximide, geneticin (G418), verrucarin A and deoxynyvalenol were obtained from Sigma-Aldrich. Cryptopleurine, nagilactone $\mathrm{C}$ and phyllanthoside were provided by NIH/NCI Developmental Therapeutics Program. When not soluble enough in water, compounds were dissolved in DMSO to achieve high concentration for stock solutions. The CCA tri-nucleotide sample was purchased from Dharmacon Thermo Scientific.

Ribosome purification, crystallization and data collection. $80 \mathrm{~S}$ ribosomes from the yeast $S$. cerevisiae were purified and crystallized as previously described ${ }^{1}$. The $80 \mathrm{~S}$ ribosome complexes with cycloheximide and lactimidomycin were obtained by incubating vacant $80 \mathrm{~S}$ ribosomes with 20 -fold excesses of each of these compounds respectively ( $30 \mu \mathrm{M}$ final concentration) for $15 \mathrm{~min}$ at $30^{\circ} \mathrm{C}$ prior to crystallization. All other ribosome-inhibitor complexes and the CCA complex were formed by soaking $80 \mathrm{~S}$ ribosome crystals with $0.3-0.7 \mathrm{mM}$ of each inhibitor for $2 \mathrm{~h}$ at $4^{\circ} \mathrm{C}$. Data collection was performed at SOLEIL synchrotron, beam line PROXIMA1. We applied the data collection strategy previously described ${ }^{1,44}$, attenuating the beam to $20 \%$ of the incoming photon flux and collecting highly redundant data when possible. Diffraction data were reduced using the XDS suite ${ }^{45}$.

Structure determination, refinement and analyses. The structures were solved by molecular replacement using the deposited 80 S ribosome structure (PDB 3U5B3U5I) as search model and then subjected to refinement using Phenix.refine ${ }^{46}$. The electron density was manually inspected to search the density corresponding to the inhibitors. Coordinates and restraints for each inhibitor were generated online with the Grade web server (Global Phasing, http://grade.globalphasing.org) using SMILES strings from PubChem database $e^{47}$. Ligands fitting and remodelling of ribosomal binding sites were performed manually using $\mathrm{Coot}^{48}$. Final refinement was performed with Phenix.refine. Crystallographic statistics are reported in Supplementary Information Table 1. Ligands geometry was validated with the software Mogul from the CCDC package ${ }^{49}$. Drawing of chemical structures was performed with MarvinSketch suite (ChemAxon, http://www.chemaxon.com/) and figures of structures were prepared using PyMOL 1.5 (Schrödinger, http://pymol.org/). Ribosomal proteins were named throughout the manuscript according to the newly established nomenclature ${ }^{50}$

Rapid kinetic methods. Fluorescence experiments were carried out in buffer A (50 mM Tris- $\mathrm{HCl}, \mathrm{pH} 7.5,70 \mathrm{mM} \mathrm{NH}_{4} \mathrm{Cl}, 30 \mathrm{mM} \mathrm{KCl}$ and $20 \mathrm{mM} \mathrm{MgCl}_{2}, 1 \mathrm{mM}$ DTT) at $20^{\circ} \mathrm{C}$ using a stopped-flow apparatus (SX-20MV; Applied Photophysics). Proflavin fluorescence was excited at $470 \mathrm{~nm}$ and detected after passing a KV500 cut-off filter (Schott). Equal volumes of ribosomes $(0.4 \mu \mathrm{M})$ and tRNA ${ }^{\text {Phe }}(\operatorname{Prf})$ $(0.15 \mu \mathrm{M})$ were rapidly mixed and the fluorescence change was monitored over time. Experiments in the presence of inhibitors (lactimidomycin or cycloheximide) were performed at different concentrations of inhibitor as indicated. Complexes for chase experiments were prepared by incubating fluorescence-labelled tRNA $(0.15 \mu \mathrm{M})$ with ribosomes $(0.4 \mu \mathrm{M})$ for $1 \mathrm{~min}$ at $4^{\circ} \mathrm{C}$. The dissociation of tRNA $^{\text {Phe }}$ (Prf) from ribosomes was induced by addition of excess non-labelled tRNA $^{\text {Phe }}(20 \mu \mathrm{M})$, lactimidomycin $(15 \mu \mathrm{M})$ or cycloheximide $(500 \mu \mathrm{M})$. Time courses were evaluated using TableCurve software by single-exponential fitting, yielding $k_{\text {app }}$ values. The dependence of $k_{\text {app }}$ values on inhibitor concentrations were fitted to hyperbolic functions. Average $k_{\text {app }}$ values and standard deviations were obtained from at least seven time courses.

Isothermal titration calorimetry. Experiments were carried out using a MicroCal ITC200 instrument (MicroCal, LLC, Northampton, MA) in buffer $(20 \mathrm{mM}$ HEPES, pH 7.5, $30 \mathrm{mM} \mathrm{KCl}, 70 \mathrm{mM} \mathrm{NH}_{4} \mathrm{Cl}, 7 \mathrm{mM} \mathrm{MgCl}_{2}$ ). Two-microlitre aliquots of cycloheximide $(70 \mu \mathrm{M}$ stock solution) were injected into the 0.2 -ml cell containing the solution of $80 \mathrm{~S}$ ribosomes $(3.7 \mu \mathrm{M})$. The resulting titration curves were fitted using MicroCal Origin software.

44. Mueller, M., Wang, M. \& Schulze-Briese, C. Optimal fine phi-slicing for single-photon-counting pixel detectors. Acta Crystallogr. D 68, 42-56 (2012).

45. Kabsch, W. Xds. Acta Crystallogr. D 66, 125-132 (2010).

46. Adams, P. D. et al. PHENIX: a comprehensive Python-based system for macromolecular structure solution. Acta Crystallogr. D 66, 213-221 (2010).

47. Bolton, E., Wang, Y., Thiessen, P. A. \& Bryant, S. H. PubChem: integrated platform of small molecules and biological activities. Annu. Rep. Comput. Chem. 4, 217-241 (2008).

48. Emsley, P., Lohkamp, B., Scott, W. G. \& Cowtan, K. Features and development of Coot Acta Crystallogr. D 66, 486-501 (2010).

49. Bruno, I. J. et al. Retrieval of crystallographically-derived molecular geometry information. J. Chem. Inf. Comput. Sci. 44, 2133-2144 (2004).

50. Ban, N. et al. A new system for naming ribosomal proteins. Curr. Opin. Struct. Biol. 24, 165-169 (2014).
51. Schneider-Poetsch, T. et al. Inhibition of eukaryotic translation elongation by cycloheximide and lactimidomycin. Nature Chem. Biol. 6, 209-217 (2010).

52. Cundliffe, E., Cannon, M. \& Davies, J. Mechanism of inhibition of eukaryotic protein synthesis by trichothecene fungal toxins. Proc. Natl Acad. Sci. USA 71, 30-34 (1974).

53. Middlebrook, J. L. \& Leatherman, D. L. Binding of T-2 toxin to eukaryotic cell ribosomes. Biochem. Pharmacol. 38, 3103-3110 (1989).

54. Ehrlich, K. C. \& Daigle, K. W. Protein synthesis inhibition by 8-oxo-12,13epoxytrichothecenes. Biochim. Biophys. Acta 923, 206-213 (1987).

55. Fresno, M., Jiménez, A. \& Vázquez, D. Inhibition of translation in eukaryotic systems by harringtonine. Eur. J. Biochem. 72, 323-330 (1977).

56. Gürel, G., Blaha, G., Moore,P. B. \& Steitz, T. A. U2504 determines the species specificity of the A-site cleft antibiotics: the structures of tiamulin, homoharringtonine, and bruceantin bound to the ribosome. J. Mol. Biol. 389, 146-156 (2009).

57. Tujebajeva, R. M., Graifer, D. M., Karpova, G. G. \& Ajtkhozhina, N. A. Alkaloid homoharringtonine inhibits polypeptide chain elongation on human ribosomes on the step of peptide bond formation. FEBS Lett. 257, 254-256 (1989).

58. Carrasco, L. Fresno, M. \& Vazquez, D. Narciclasine: an antitumour alkaloid which blocks peptide bond formation by eukaryotic ribosomes. FEBS Lett. 52, 236-239 (1975).

59. Baez, A. \& Vazquez, D. Binding of [3H]narciclasine to eukaryotic ribosomes. A study on a structure-activity relationship. Biochim. Biophys. Acta 518, 95-103 (1978).

60. Jimenez, A., Santos, A., Alonso, G. \& Vazquez, D. Inhibitors of protein synthesis in eukarytic cells. Comparative effects of some amaryllidaceae alkaloids. Biochim. Biophys. Acta 425, 342-348 (1976).

61. Kukhanova, M., Victorova, L. \& Krayevsky, A. Peptidyltransferase center of ribosomes. On the mechanism of action of alkaloid lycorine. FEBS Lett. 160, 129-133 (1983).

62. Grollman, A. P. Inhibitors of protein biosynthesis. II. Mode of action of anisomycin J. Biol. Chem. 242, 3226-3233 (1967).

63. Hansen, J. L., Moore, P. B. \& Steitz, T. A. Structures of five antibiotics bound at the peptidyl transferase center of the large ribosomal subunit. J. Mol. Biol. 330, 1061-1075 (2003)

64. Yamaguchi, H., Yamamoto, C. \& Tanaka, N. Inhibition of protein synthesis by blasticidin S. I. Studies with cell-free systems from bacterial and mammalian cells. J. Biochem. 57, 667-677 (1965).

65. Svidritskiy, E., Ling, C., Ermolenko, D. N. \& Korostelev, A. A. Blasticidin S inhibits translation by trapping deformed tRNA on the ribosome. Proc. Natl Acad. Sci. USA 110, 12283-12288 (2013).

66. Eustice, D. C. \& Wilhelm, J. M. Mechanisms of action of aminoglycoside antibiotics in eucaryotic protein synthesis. Antimicrob. Agents Chemother. 26, 53-60 (1984).

67. Manuvakhova, M., Keeling, K. \& Bedwell, D. M. Aminoglycoside antibiotics mediate context-dependent suppression of termination codons in a mammalian translation system. RNA 6, 1044-1055 (2000).

68. Contreras, A., Vazquez, D. \& Carrasco, L. Inhibition, by selected antibiotics, of protein synthesis in cells growing in tissue cultures. J. Antibiot. 31, 598-602 (1978).

69. Brodersen, D. E. et al. The structural basis for the action of the antibiotics tetracycline, pactamycin, and hygromycin B on the $30 \mathrm{~S}$ ribosomal subunit. Cell 103, 1143-1154 (2000).

70. Dinos, G. et al. Dissecting the ribosomal inhibition mechanisms of edeine and pactamycin: the universally conserved residues $\mathrm{G} 693$ and $\mathrm{C} 795$ regulate $\mathrm{P}$-site RNA binding. Mol. Cell 13, 113-124 (2004).

71. Bucher, K. \& Skogerson, L. Cryptopleurine-an inhibitor of translocation. Biochemistry 15, 4755-4759 (1976).

72. Kozak, M. \& Shatkin, A. J. Migration of 40 S ribosomal subunits on messenger RNA in the presence of edeine. J. Biol. Chem. 253, 6568-6577 (1978)

73. Pioletti, M. et al. Crystal structures of complexes of the small ribosomal subunit with tetracycline, edeine and IF3. EMBO J. 20, 1829-1839 (2001).

74. Dehoux, P.. Davies, J. \& Cannon, M. Natural cycloheximide resistance in yeast. The role of ribosomal protein L41. Eur. J. Biochem. 213, 841-848 (1993).

75. Kawai, S. et al. Drastic alteration of cycloheximide sensitivity by substitution of one amino acid in the L41 ribosomal protein of yeasts. J. Bacteriol. 174, 254-262 (1992).

76. Schultz, L. D. \& Friesen, J. D. Nucleotide sequence of the $\mathrm{tcm} /$ gene (ribosomal protein L3) of Saccharomyces cerevisiae. J. Bacteriol. 155, 8-14 (1983).

77. Koshinsky, H. A., Schappert, K. T. \& Khachatourians, G. G. Isolation and characterization of Saccharomyces cerevisiae mutants resistant to T-2 toxin. Curr. Genet. 13, 363-368 (1988)

78. Adam, G. et al. Molecular mechanisms of deoxynivalenol resistance in the yeast Saccharomyces cerevisiae. Mycotoxin Res. 17 (Suppl. 1), 19-23 (2001).

79. Jimenez, A., Sanchez, L. \& Vazquez, D. Simultaneous ribosomal resistance to trichodermin and anisomycin in Saccharomyces cerevisiae mutants. Biochim. Biophys. Acta 383, 427-434 (1975).

80. Hobden, A. N. \& Cundliffe, E. Ribosomal resistance to the 12,13 epoxytrichothecene antibiotics in the producing organism Myrothecium verrucaria. Biochem. J. 190, 765-770 (1980).

81. Jimenez, A., Sanchez, L. \& Vazquez, D. Location of resistance to the alkaloid narciclasine in the 60S ribosomal subunit. FEBS Lett. 55, 53-56 (1975).

82. Nelson, J. A. E., Savereide, P. B. \& Lefebvre, P. A. The CRY1 gene in Chlamydomonas reinhardtii: structure and use as a dominant selectable marker for nuclear transformation. Mol. Cell. Biol. 14, 4011-4019 (1994).

83. Paulovich, A. G., Thompson, J. R., Larkin, J. C., Li, Z. \& Woolford, J. L. Jr. Molecular genetics of cryptopleurine resistance in Saccharomyces cerevisiae: expression of a ribosomal protein gene family. Genetics 135, 719-730 (1993). 


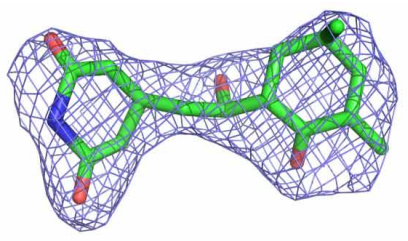

Cycloheximide

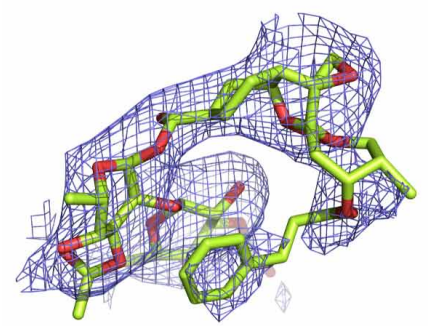

Phyllanthoside

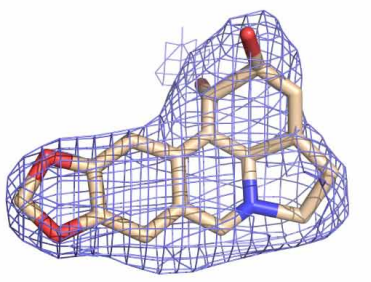

Lycorine

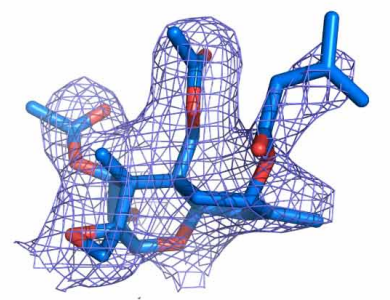

T2-toxin

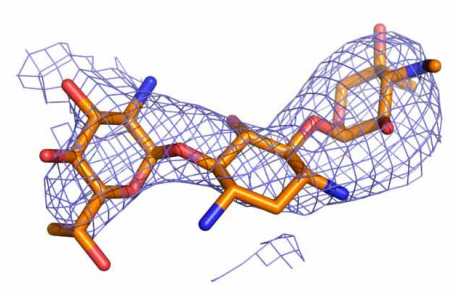

Geneticin G418

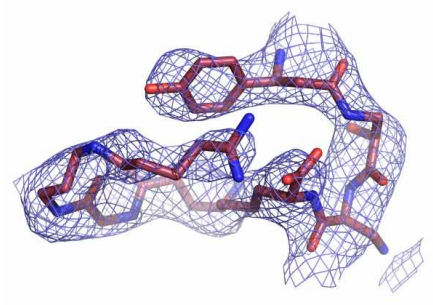

Edeine

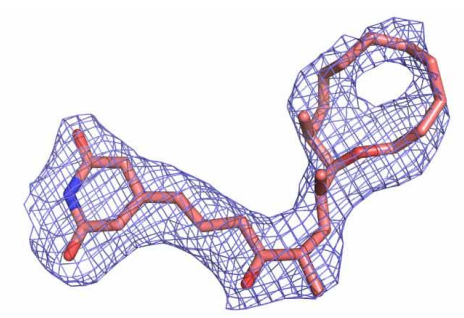

Lactimidomycin

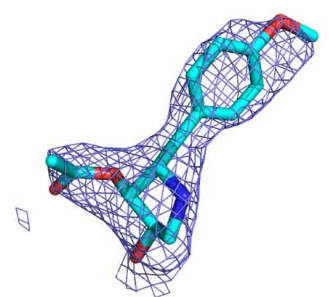

Anisomycin

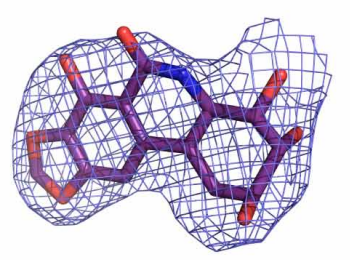

Narciclasine

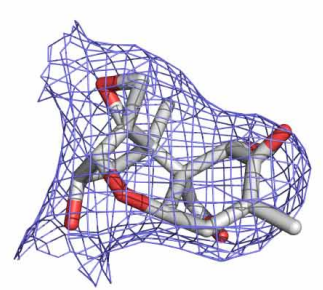

Deoxynivalenol

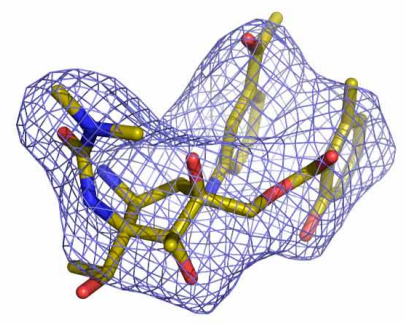

Pactamycin

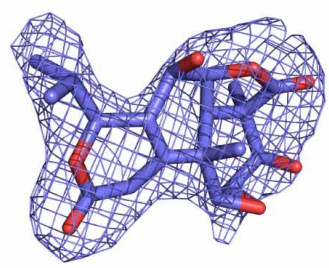

Nagilactone $C$

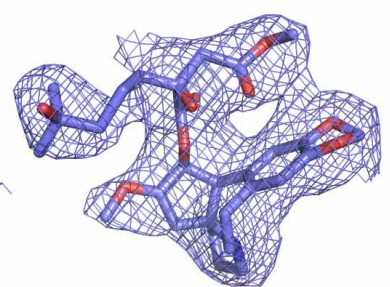

Homoharringtonine
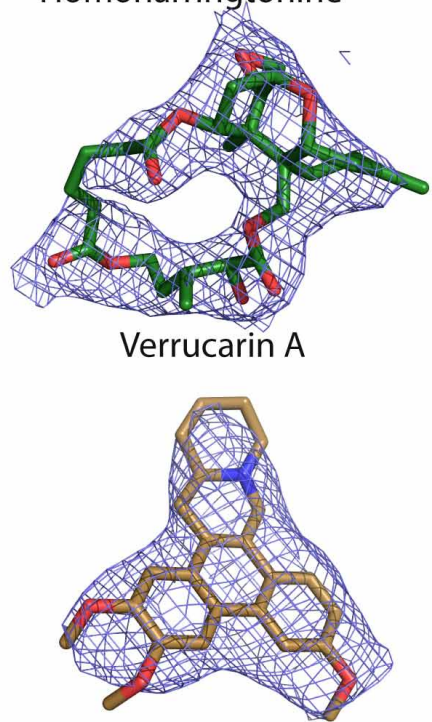

Cryptopleurine

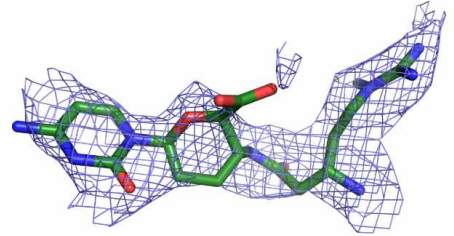

Blasticidine S

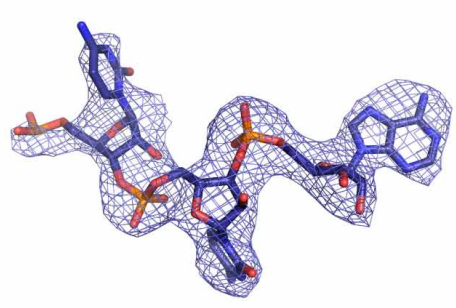

Extended Data Figure 1 | Unbiased positive electron density of smallmolecule inhibitors and CCA-trinucleotide. $F_{\mathrm{o}}-F_{\mathrm{c}}$ positive electron density

maps of the 16 small-molecule inhibitors and the CCA tri-nucleotide. The maps were contoured at $3.0-3.5 \sigma$. 


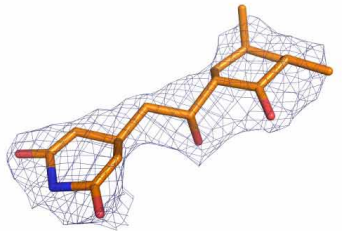

Cycloheximide

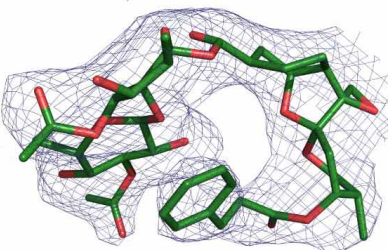

Phyllanthoside

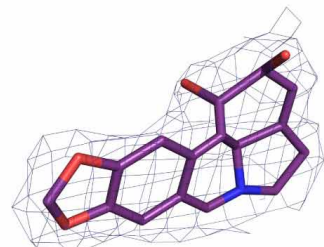

Lycorine

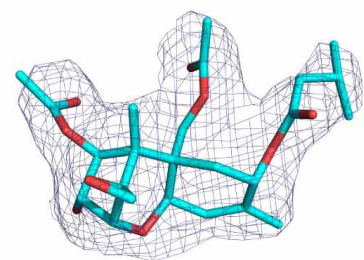

T2-toxin

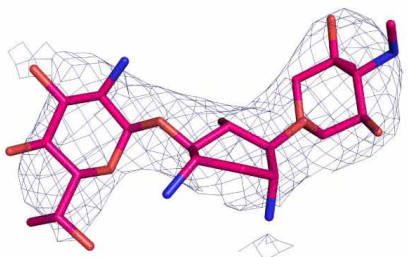

Geneticin G418

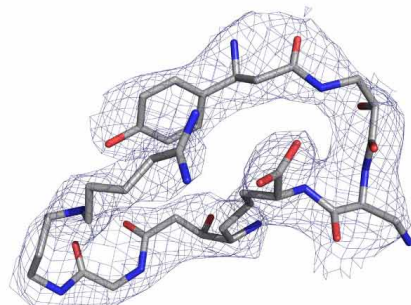

Edeine

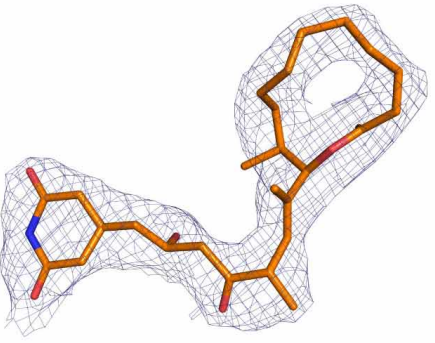

Lactimidomycin

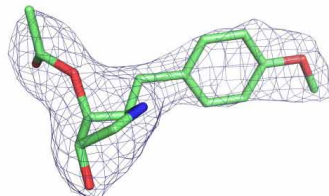

Anisomycin

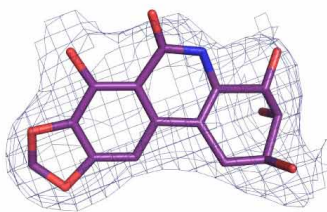

Narciclasine

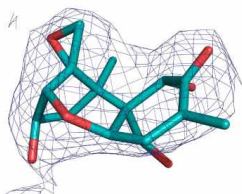

Deoxynivalenol

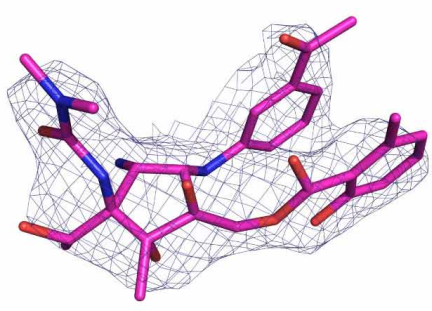

Pactamycin

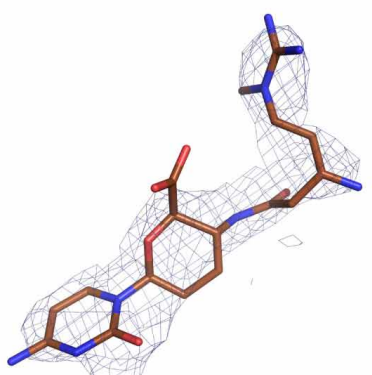

Blasticidine S

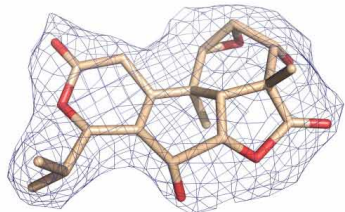

Nagilactone C

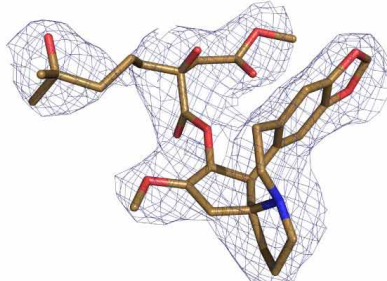

Homoharringtonine

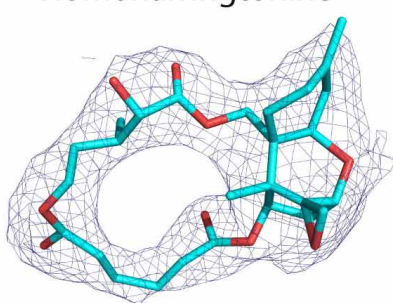

Verrucarin A

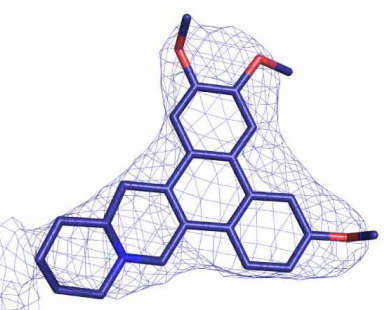

\section{Cryptopleurine}

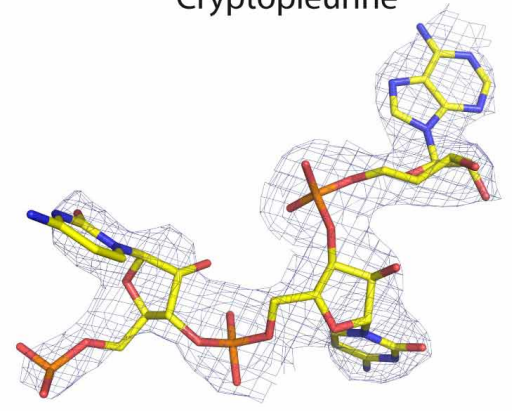

CCA

Extended Data Figure $2 \mid$ Electron density of small-molecule inhibitors and CCA-trinucleotide. $2 F_{\mathrm{o}}-F_{\mathrm{c}}$ electron density maps of the 16 small-molecule inhibitors and the CCA tri-nucleotide. The maps were contoured at 1.0-1.5 $\sigma$. 
Homoharringtonine

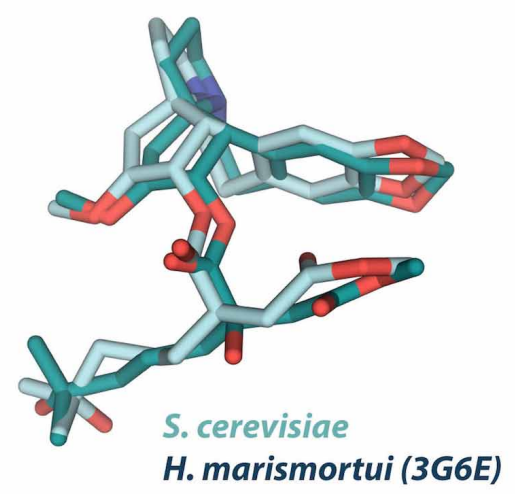

Blasticidin S

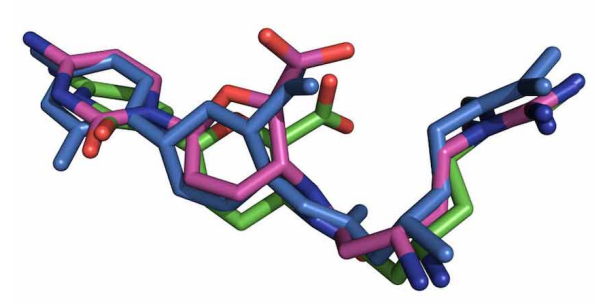

S. cerevisiae

H. marismortui (1KC8)

T. thermophilus (4L6L)

Extended Data Figure $3 \mid$ Structures of homoharringtonine, anisomycin, blasticidin $S$ and pactamycin in eukaryotes, archaea and bacteria.

Complexes with bacterial and archaeal structures were aligned with the $25 \mathrm{~S}$ rRNA or the $18 \mathrm{~S}$ rRNA of the yeast ribosome. Differences in the binding pocket
Anisomycin

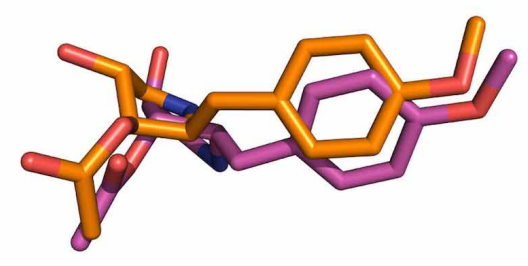

S. cerevisiae

H. marismortui (1K73)

Pactamycin

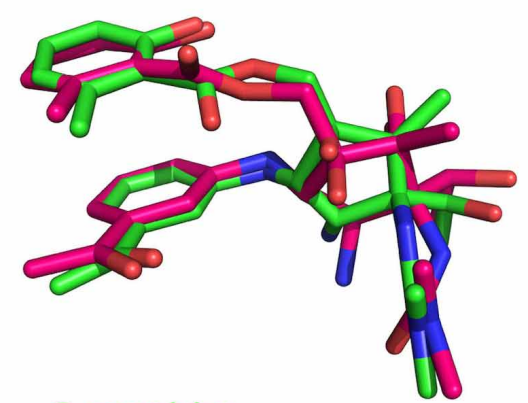

\section{S. cerevisiae}

T. thermophilus (1HNX)

were found only in the case of anisomycin as described in Extended Data Fig. 8. Coordinates were taken from the PDB databank; PDB entries are indicated in parentheses. 


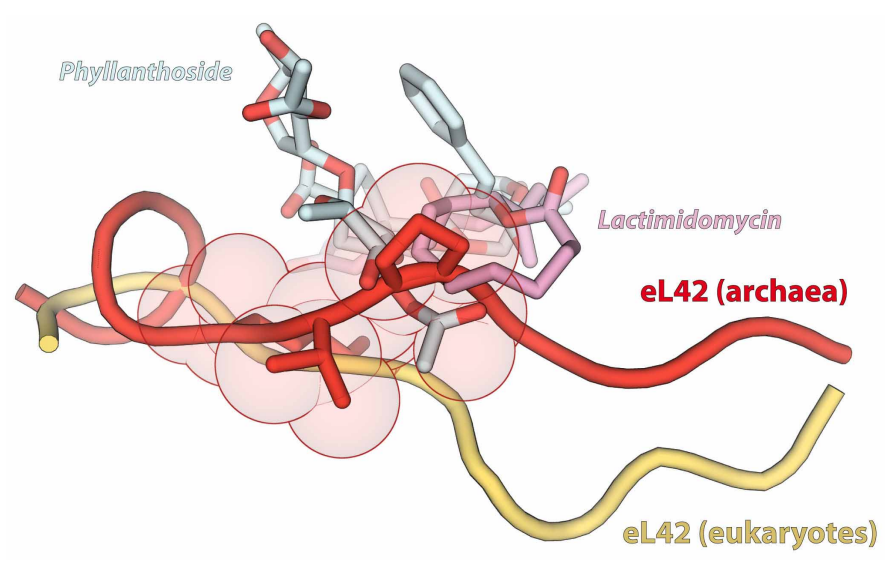

Extended Data Figure $4 \mid$ Structural differences in protein eL42 may preclude the binding of lactimidomycin and phyllanthoside to the archaeal

ribosome. In archaea, the protein eL42 (in red, PDB 1JJ2) is shorter than its eukaryotic counterpart (yellow) and adopts a markedly different conformation that clashes with lactimidomycin (pink) and phyllanthoside (cyan). Residues of protein eL42 from archaea involved in the steric clash with both inhibitors are depicted in red with sticks and van der Waals spheres. Although the 60S tRNA E-site is targeted by small-molecule inhibitors in archaea and eukaryotes, remarkably no antibiotics targeting this site in bacteria have been described. 


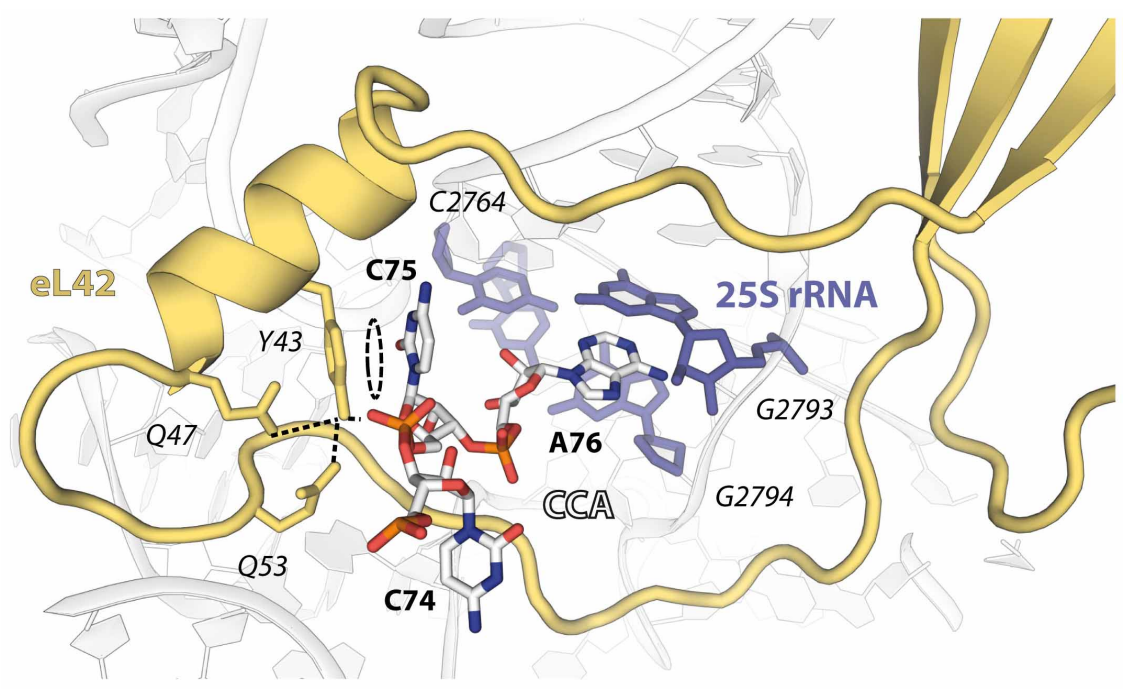

Extended Data Figure 5 Close-up view of CCA tri-nucleotide binding site. CCA tri-nucleotide (white) bound to the 60S tRNA E-site. The binding pocket is formed by $25 \mathrm{~S}$ rRNA nucleotides (blue) and part of protein eL42 (yellow). In eukaryotes, the protein eL42 remodels the 60S E-site and

participates actively in positioning the CCA-end. Although C75 is stabilized by stacking and hydrogen bonds interactions with eL42, the terminal residue A76 of deacylated tRNA enters the pocket and forms a non-canonical base pair with a conserved residue of the $25 \mathrm{~S}$ rRNA. 
a

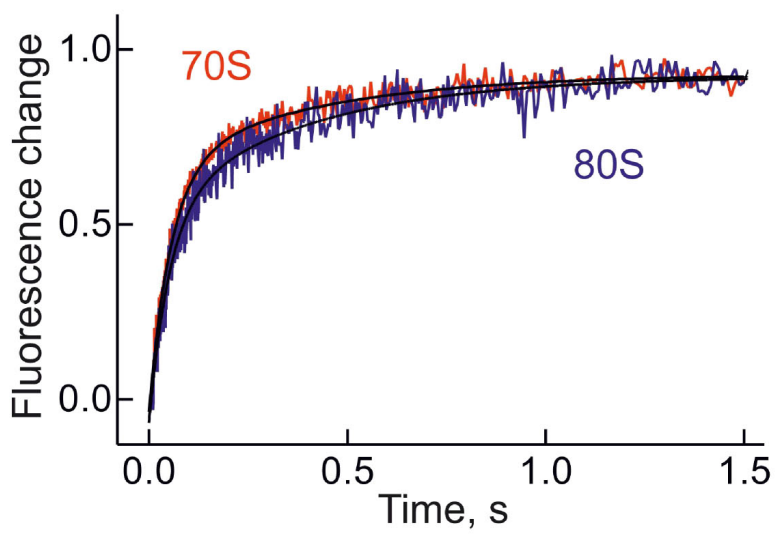

b
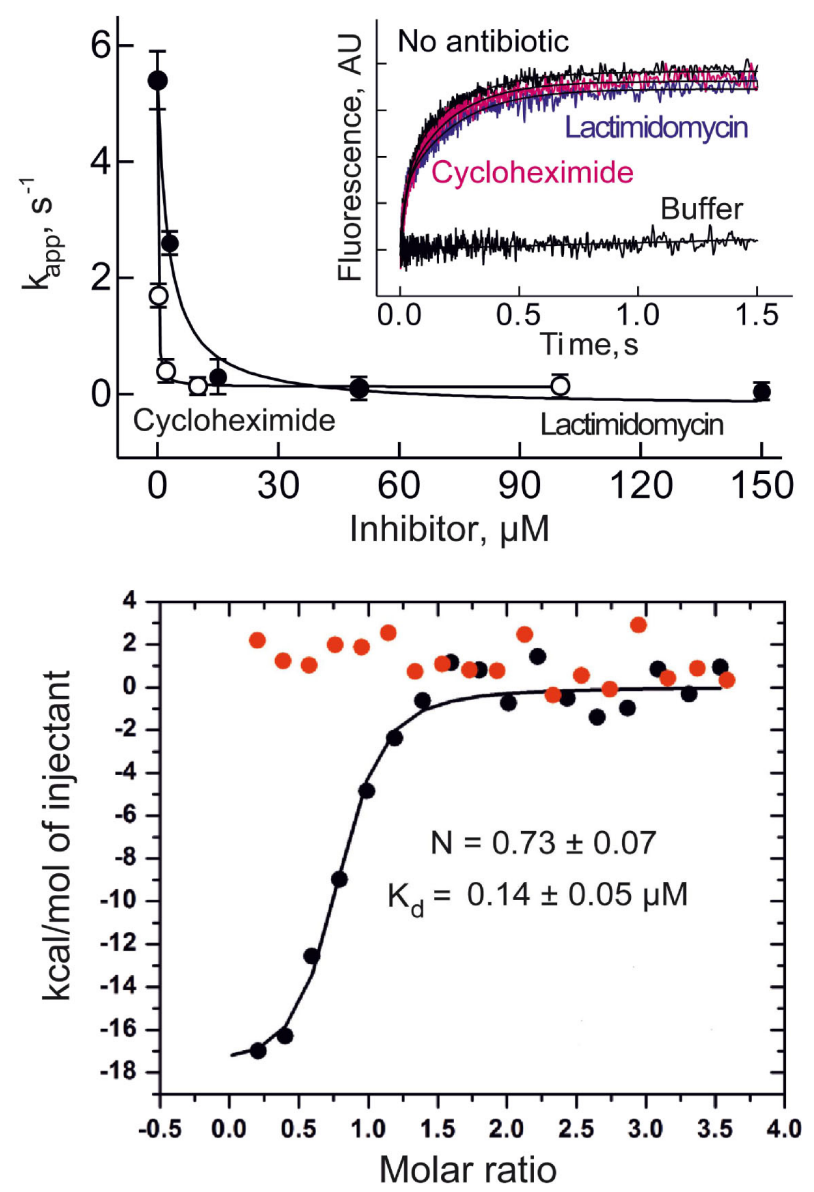

Extended Data Figure 6 Kinetic study of lactimidomycin and cycloheximide. a, Deacylated tRNA binding to the bacterial $70 \mathrm{~S}$ and eukaryotic $80 \mathrm{~S}$ ribosomes. Time courses of tRNA ${ }^{\text {Phe }}$ (Prf) binding to the $S$. cerevisiae $80 \mathrm{~S}$ (blue) and E. coli $70 \mathrm{~S}$ (red) ribosomes measured by the stopped-flow technique. b. Competition binding assays. Dose response curves for lactimidomycin (closed circles) and cycloheximide (open circles). Inset, the binding of the tRNA to the 70S ribosome was not affected in the presence of lactimidomycin (blue) and cycloheximide (magenta). Control without inhibitors is shown in black. c, Measurement of cycloheximide affinity to the $80 \mathrm{~S}$ ribosome by isothermal titration calorimetry. The curves present the thermodynamic parameters of cycloheximide binding to $80 \mathrm{~S}$ ribosomes (black circles) and control buffer (red circles). N, number of binding sites. The affinity was determined in 4 independent experiments. 


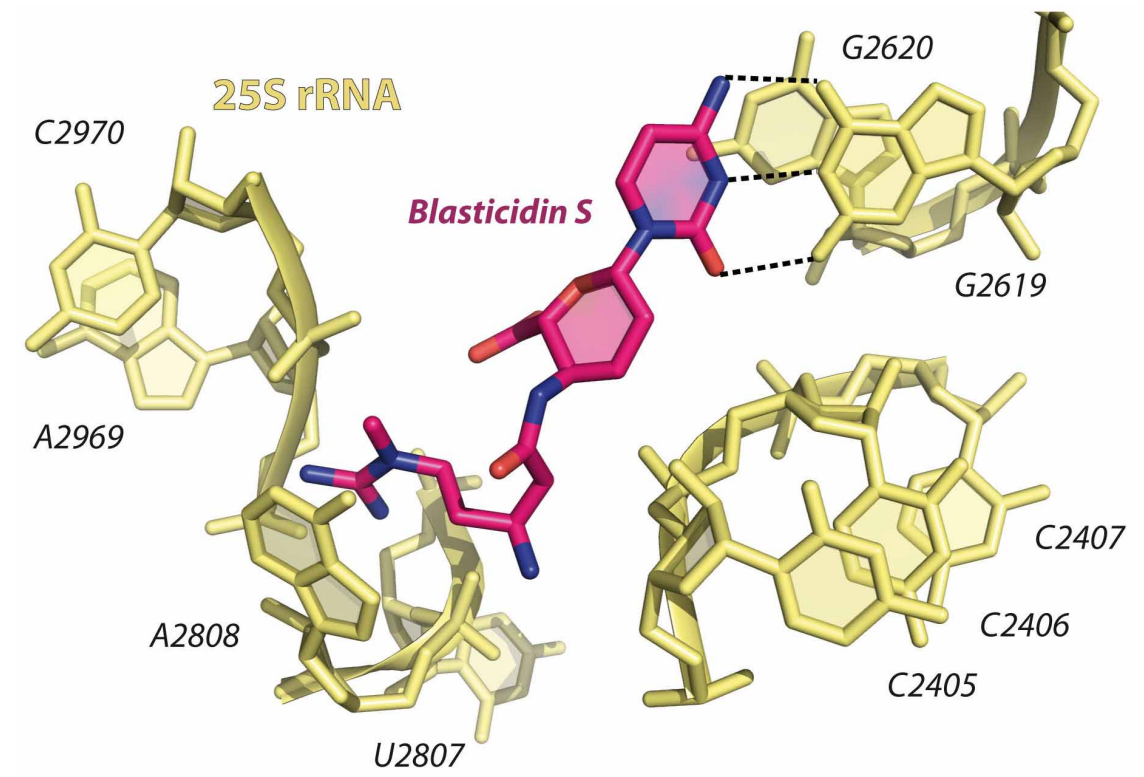

Extended Data Figure $7 \mid$ Close-up view of blasticidin S binding site. Blasticidin S (pink) bound to the 60S tRNA P-site. The binding pocket is formed exclusively by nucleotides of the $25 \mathrm{~S}$ rRNA (yellow). Dashed lines

indicate hydrogen contacts with G2619 that precludes the formation of the base pair with C75 of the tRNA in the P-site. 
a

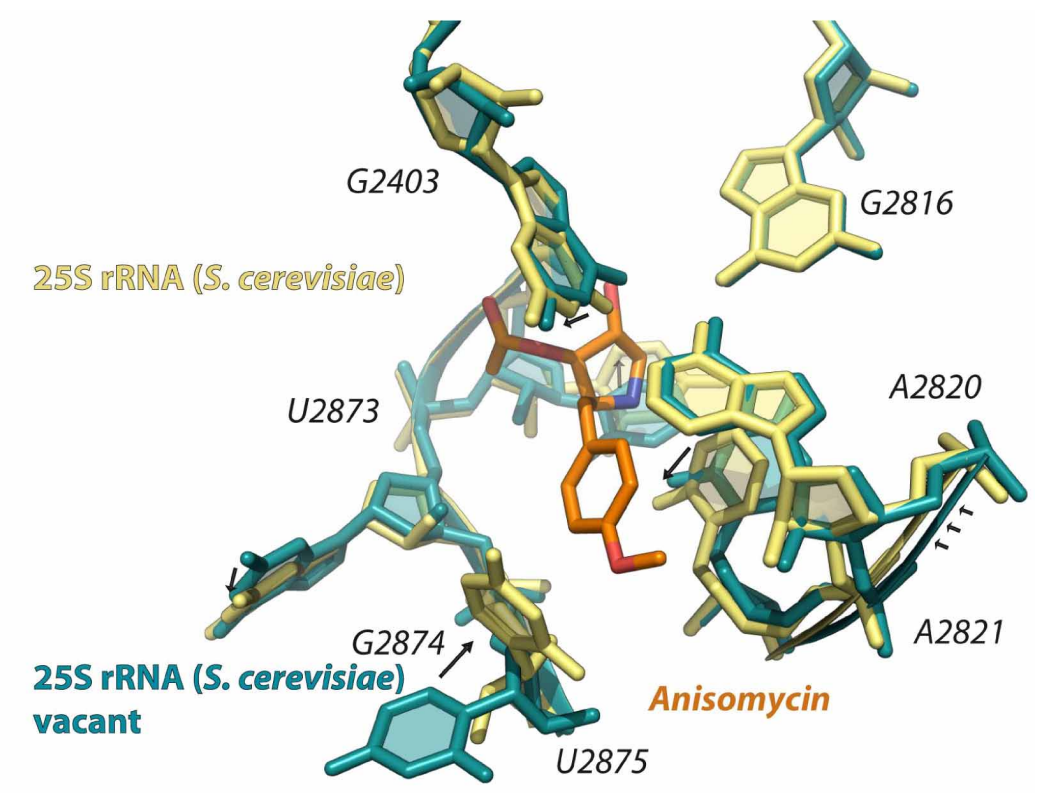

b

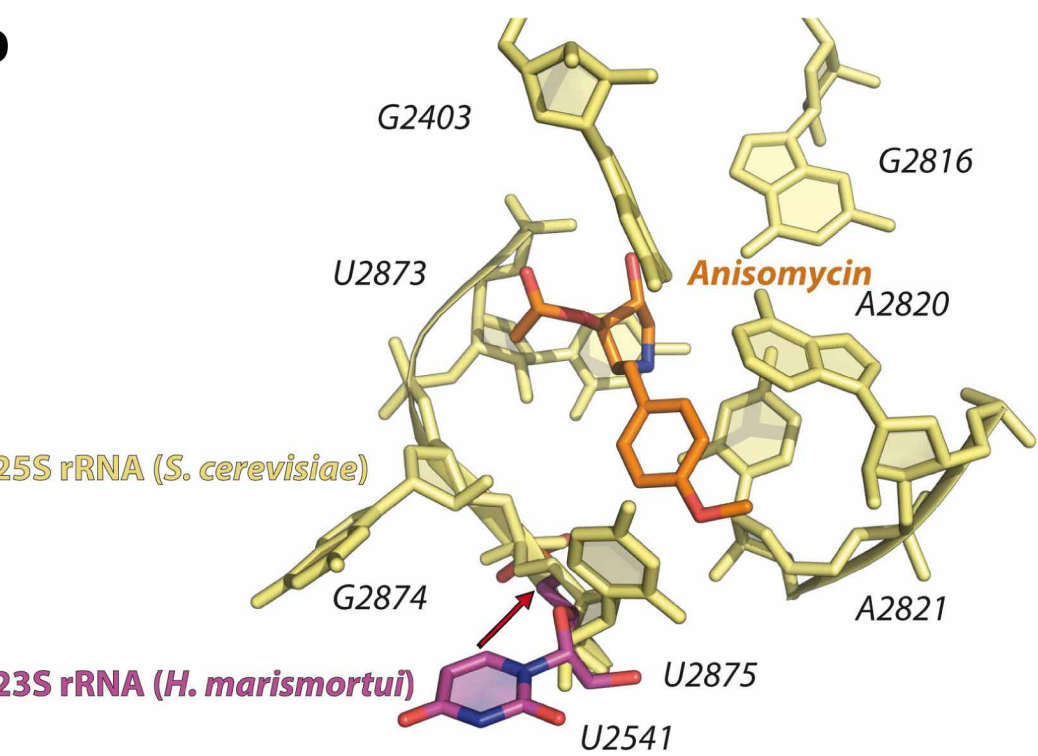

Extended Data Figure $8 \mid$ Conformational changes in the peptidyl transferase centre and differences with the archaeal ribosome. a, A-site inhibitors induce conformational changes upon binding to the peptidyl transferase centre of the yeast ribosome. Superimposition of the vacant $80 \mathrm{~S}$ ribosome (PDB 3U5A-3U5D, blue) and the 80 S ribosome in complexes with A-site inhibitors (25S rRNA in yellow). The structure of anisomycin (orange) was chosen as a reference to represent the peptidyl transferase centre A-site inhibitors. Residue U2875 (U2506) undergoes the most drastic change resulting in the breakdown of a canonical base pair formed by G2952 (U2583) and its subsequent flipping out. The reorientation of U2875 (U2506) participates in preventing the binding of aminoacyl-tRNA. b, U2875 adopts a different conformation upon binding of anisomycin (orange) to the peptidyl transferase centre A-site (yellow) in eukaryotes in contrast to its homologue (U2541) in archaea (magenta). Superimposition of the 50S large subunit from $H$. marismortui in complex with anisomycin (PDB 1K73) and the $80 \mathrm{~S}$ ribosome in complex with anisomycin. 
RESEARCH ARTICLE

Extended Data Table 1 | Summary of information for the 16 small-molecule inhibitors

Bibliographic references

\begin{tabular}{|c|c|c|c|c|c|c|c|c|c|}
\hline Name & Acronym & Type & Origin & Spectrum & Site & X-ray data & $\begin{array}{c}\text { Translation } \\
\text { inhibition }\end{array}$ & $\begin{array}{c}\text { Direct } \\
\text { binding }\end{array}$ & $\begin{array}{c}\text { Functional } \\
\text { study }\end{array}$ \\
\hline Cycloheximide & $\mathrm{CHX}$ & Glutarimides & Bacteria & $E$ & 60S E-site & - & 51 & 15 & 51 \\
\hline Lactimidomycin & LTM & Glutarimides & Bacteria & $\mathrm{E}$ & $60 S$ E-site & - & 51 & - & 51 \\
\hline Phyllanthoside & PHY & Phyllanthus glycosides & Plant & $E$ & 60S E-site & - & 17 & - & 17 \\
\hline T2-toxin & T2T & Trichothecenes & Fungi & $E$ & $60 S$ A-site PTC & - & 52 & 53 & 52 \\
\hline Deoxynivalenol & DON & Trichothecenes & Fungi & $E$ & $60 S$ A-site PTC & - & 54 & - & 54 \\
\hline Verrucarin & VER & Trichothecenes & Fungi & $\mathrm{E}$ & $60 S$ A-site PTC & - & 52 & - & 52 \\
\hline Homoharringtonine & НHT & Cephalotaxus alkaloids & Plant & $E$ & $60 S$ A-site PTC & $+(H)$ & 55 & 56 & 57 \\
\hline Narciclasine & NAR & Amaryllidaceae alkaloids & Plant & $\bar{E}$ & $60 S$ A-site PTC & - & 58 & 59 & 58 \\
\hline Lycorine & LYC & Amaryllidaceae alkaloids & Plant & $E$ & $60 S$ A-site PTC & - & 60 & - & 61 \\
\hline Nagilactone C & NAG & Norditerpene dilactone & Plant & $\mathrm{E}$ & $60 S$ A-site PTC & - & 17 & - & 17 \\
\hline Anisomycin & ANI & Polysubstituted pyrrolidine & Bacteria & $E$ & 60S A-site PTC & $+(H)$ & 62 & 63 & 62 \\
\hline Blasticidin S & BLA & Nucleoside & Bacteria & $\mathrm{B} E$ & $60 S$ P-site PTC & $+(T, H)$ & 64 & 63,65 & 65 \\
\hline Geneticin (G418) & GEN & Aminoglycosides & Bacteria & B E & $40 S \mathrm{DC}$ & - & 66 & - & 67 \\
\hline Pactamycin & PAC & Minocyclopentitol & Bacteria & $B E$ & 40S E-site & $+(T)$ & 68 & 69 & 70 \\
\hline Cryptopleurine & CRY & Cryptocarya alkaloids & Plant & $E$ & 40S E-site & - & 71 & 35 & 71 \\
\hline Edeine & EDE & Polyamine peptide & Bacteria & B E & 40S P-site & $+(T)$ & 72 & 73 & 70,72 \\
\hline
\end{tabular}

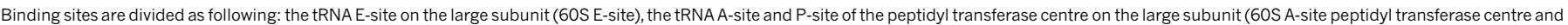

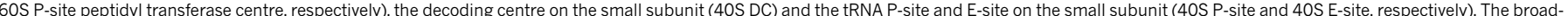

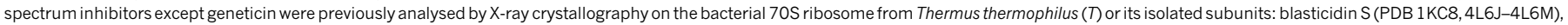
pactamycin (PDB 1HNX) and edeine (PDB 1195). Similarly, structural data of complexes with the archaeal Haloarcula marismortui (H) 50S subunit are available for anisomycin (PDB 1K73, 3CC4) and

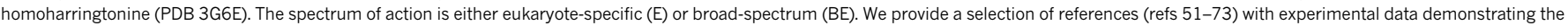
inhibition of protein synthesis in eukaryotes, direct binding to the ribosome and functional characterization of the inhibitors when available. 
Extended Data Table 2 | Resistant mutations in proteins of the yeast ribosome

\begin{tabular}{|c|c|c|c|}
\hline Name & Acronym & $\begin{array}{c}\text { Resistance mutation } \\
\text { in yeast }\end{array}$ & $\begin{array}{l}\text { Functional } \\
\text { study }\end{array}$ \\
\hline Cycloheximide & $\mathrm{CHX}$ & eL42: P56Q or uL15: Q38E & Refs $42,74,75$ \\
\hline Lactimidomycin & LTM & eL42: P56Q or uL15: Q38E & Ref 18 \\
\hline T2-toxin & T2T & uL3: W255C & Refs 76,77 \\
\hline Deoxynivalenol & DON & uL3: W255C & Refs 76,78 \\
\hline Verrucarin & VER & uL3: W255C & Refs 76,79 \\
\hline Homoharringtonine & HНT & uL3: W255C & Refs 76,80 \\
\hline Narciclasine & NAR & uL3: W255C & Refs 76,81 \\
\hline Anisomycin & ANI & uL3: W255C & Refs 76,79 \\
\hline Cryptopleurine & CRY & uS11: L138S or L138stop & Refs 82,83 \\
\hline
\end{tabular}

Referenced functional studies (refs 74-83) are listed. 